\title{
BMJ Open Combining modifiable risk factors and risk of dementia: a systematic review and meta-analysis
}

\author{
Ruth Peters, ${ }^{1,2,3}$ Andrew Booth, ${ }^{4}$ Kenneth Rockwood, ${ }^{5}$ Jean Peters, ${ }^{4}$ \\ Catherine D'Este, ${ }^{6,7}$ Kaarin J Anstey ${ }^{1,3}$
}

To cite: Peters R, Booth A, Rockwood K, et al. Combining modifiable risk factors and risk of dementia: a systematic review and meta-analysis. BMJ Open 2019;9:e022846. doi:10.1136/ bmjopen-2018-022846

- Prepublication history and additional material for this paper are available online. To view these files, please visit the journal online (http://dx.doi. org/10.1136/bmjopen-2018022846).

Received 16 March 2018

Revised 9 August 2018

Accepted 15 November 2018

Check for updates

(c) Author(s) (or their employer(s)) 2019. Re-use permitted under CC BY-NC. No commercial re-use. See rights and permissions. Published by BMJ.

${ }^{1}$ Neuroscience Research Australia, Sydney, New South Wales, Australia

${ }^{2}$ School of Public Health, Imperial College London, London, UK

${ }^{3}$ University of New South Wales, Sydney, New South Wales, Australia

${ }^{4}$ School of Health and Related Research (ScHARR), University of Sheffield, Sheffield, UK

${ }^{5}$ Dalhousie University, Halifax, Nova Scotia, Canada

${ }^{6}$ Australian National University (ANU), Canberra, Australian Capital Territory, Australia

${ }^{7}$ University of Newcastle, Callaghan, New South Wales, Australia

Correspondence to

Dr Ruth Peters;

r.peters@imperial.ac.uk

\section{ABSTRACT}

Objective To systematically review the literature relating to the impact of multiple co-occurring modifiable risk factors for cognitive decline and dementia.

Design A systematic review and meta-analysis of the literature relating to the impact of co-occurring key risk factors for incident cognitive decline and dementia. All abstracts and full text were screened independently by two reviewers and each article assessed for bias using a standard checklist. A fixed effects meta-analysis was undertaken.

Data sources Databases Medline, Embase and PsycINF0 were searched from 1999 to 2017.

Eligibility criteria For inclusion articles were required to report longitudinal data from participants free of cognitive decline at baseline, with formal assessment of cognitive function or dementia during follow-up, and an aim to examine the impact of additive or clustered comorbid risk factor burden in with two or more core modifiable risk factors.

Results Seventy-nine full-text articles were examined. Twenty-two articles (18 studies) were included reporting data on $>40000$ participants. Included studies consistently reported an increased risk associated with greater numbers of intraindividual risk factors or unhealthy behaviours and the opposite for healthy or protective behaviours. A meta-analysis of studies with dementia outcomes resulted in a pooled relative risk for dementia of 1.20 (95\% Cl 1.04 to 1.39) for one risk factor, 1.65 (95\% $\mathrm{Cl} 1.40$ to 1.94$)$ for two and 2.21 (95\% $\mathrm{Cl} 1.78$ to 2.73$)$ for three or more, relative to no risk factors. Limitations include dependence on published results and variations in study outcome, cognitive assessment, length of follow-up and definition of risk factor exposure.

Conclusions The strength of the reported associations, the consistency across studies and the suggestion of a dose response supports a need to keep modifiable risk factor exposure to a minimum and to avoid exposure to additional modifiable risks. Further research is needed to establish whether particular combinations of risk factors confer greater risk than others.

PROSPERO registration number 42016052914.

\section{BACKGROUND}

Modifiable risk factors for cognitive decline and dementia are now well established and several are similar to those for cancer

\section{Strengths and limitations of this study}

This is the first systematic robust evaluation of the evidence relating to impact of co-occurring modifiable risk factors for incident dementia and cognitive decline.

- Strengths of this review include use of Cochranebased methodology with a robust search strategy, detailed search terms and successful coverage of the data resulting in representation of study populations from 18 studies and 9 countries across Europe, Australia and North America with $>40000$ participants and follow-up from midlife and late life.

- Limitations include a lack of representation from other parts of the world and a restricted opportunity for evidence synthesis due to variability in reporting of individual study results.

- Data were able to be combined for 5 of the 18 studies.

and cardiovascular disease. ${ }^{1}{ }^{2}$ In particular, these include smoking, low physical activity, sedentary lifestyle, poor diet, excess alcohol consumption, midlife obesity, high blood pressure, midlife high cholesterol and diabetes. Depression, low social engagement and low cognitive engagement have also been linked to risk of late-life dementia. ${ }^{2}$

To date, the literature linking such risk factors to incident cognitive decline and dementia has typically focused on the relationship between an individual risk factor and later cognitive outcome. Despite this, we know that the clustering or co-occurring of risk factors is the more likely scenario. ${ }^{3-5}$ Population observed risk factor clusters typically include smoking, excess alcohol intake, poor diet and low levels of exercise. ${ }^{3-5}$ However, although the best evidence for reduction in risk of cognitive decline comes from multifactorial clinical trials targeting multiple risk factors ${ }^{6}$ there remains a lack of knowledge relating to the impact of risk factor burden and its composition. Targeting of effective public health risk 
reduction strategies for cognitive decline and dementia first requires identification of the 'at-risk' population. This, in turn, requires an understanding of the impact of co-occurring modifiable risk factors and the role of risk factor combinations or clusters (commonly occurring risk factor combinations) on incident dementia and cognitive decline.

Our objective is to systematically examine the literature addressing clustering or co-occurring modifiable risk factors for incident cognitive decline and dementia within individuals, and to estimate, using meta-analysis, the impact of exposure to one or more modifiable risk factors compared with absence of risk factors on the risk of future cognitive decline and dementia.

\section{METHODS}

The databases Medline, Embase and PsycINFO were searched for articles published between January 1999 and March 2017 using the search terms (cluster* or cluster analysis or summative or score or scoring or scale or scales or measure or measurement or additive or cumulative) AND (dementia or Alzheimer* or cognitive or cognition disorders) AND risk factors, limited to Adults and English language publications. See online supplementary text 1 for details. To maximise identification of eligible studies, online supplementary focused electronic searches were undertaken to include scoring-related terms and cluster-related terms separately with risk factors, vascular risk factors and 'vrf'. Reference lists of the included articles were also reviewed (online supplementary text 1 ).

\section{Inclusion criteria}

- Longitudinal studies with an explicit aim to examine the impact of additive or clustered modifiable risk factor burden for combinations of multiple core modifiable dementia risk factors (hypertension or high blood pressure, hypercholesterolaemia or high cholesterol, diabetes, high body mass index, smoking, excess alcohol, low physical activity and poor diet).

- Some evidence or clear implication that participants were free of cognitive decline or dementia at baseline assessment.

- Use of formal assessment of cognitive function or dementia or clear implication that formal dementia diagnosis took place (eg, cognitive decline assessed using general screening or neuropsychological testing, dementia diagnosis using standard diagnostic tools).

- Report of cognitive decline or dementia outcomes.

\section{Exclusion criteria}

- Non-English publications (in the absence of resources for translation).

- Studies based solely on medical records without systematic assessment of risk factors.

- Since the modifiable risk factors for dementia are primarily thought to commence their influence from early adult to mid-adult life, publications relating to non-adult populations were excluded.

- Publications with delirium as a primary end point and those including populations with cerebral autosomal dominant arteriopathy with subcortical infarcts and leukoencephalopathy (CADISIL) were excluded. Delirium is associated with acute cognitive decline and CADISIL populations have particular risk factor characteristics and are at high risk of subcortical dementia occurring in middle age or early old age.

- Publications reporting results for metabolic syndrome as a unitary risk factor were excluded. Metabolic syndrome represents a single particular cluster of vascular risk factors (usually defined as a requirement for 3/5 from obesity, high blood pressure, high plasma glucose, high serum triglycerides, low high-density lipoprotein levels) and its impact has already been examined systematically. ${ }^{78}$

- As we were seeking to examine the impact of modifiable risk factors, we excluded studies that included non-modifiable risk factors as an integral part of their risk measure, that is, where we could not evaluate the impact of modifiable risk factor burden.

- Finally, we excluded comments, letters, editorials, guidelines, consensus documents and conference proceedings.

Search strategies were co-designed by a qualified information professional $(\mathrm{AB})$ and the principal investigator (RP) who conducted the literature searches. Screening of abstracts, or titles where abstracts were unavailable, was performed independently by two reviewers (RP, JP) with each reviewer compiling a list of studies for potential inclusion. The two reviewers compared lists with differences being resolved by discussion. Full-text copies of the selected papers were obtained by the principal investigator and assessed independently for inclusion by each reviewer. Reference lists of the selected manuscripts were screened to identify other potentially relevant published papers.

Data were extracted independently by each reviewer and included papers were independently assessed for quality by both reviewers. An overall agreed risk of bias judgement was arrived at by consensus. A formal quality scoring scheme was not used as these can have poor discriminant ability; however, each paper was assessed against the key factors adapted from the Critical Appraisal Skills Programme checklists for evaluating randomised controlled trials and cohort studies, respectively (http:// www.casp-uk.net/casp-tools-checklists).

Data relating to the population reported in each study (number, age at baseline, $\%$ female at baseline), plus length of follow-up, risk factors included and where applicable, cut-off points used to define presence of risk factor, cognitive outcomes, methods of risk factor combination and analysis, covariates and reported results were extracted to a standard data extraction form. Where various versions of the results were available, the most conservative, most adjusted results were selected. Narrative 
synthesis was applied to describe and summarise the results of the included studies. Where summary measures included OR, HR or relative risks (RR), data relating to impact of clustering, defined as specific co-occurring risk factors or number of co-occurring modifiable risk factors were combined using meta-analytic techniques. The $\mathrm{I}^{2}$ measure was used to assess the percentage of variation across studies due to heterogeneity rather than chance. Where possible, publication bias was also examined using Egger's test and visual inspection of funnel plots.

The protocol for this review is registered with PROSPERO: the International prospective register of systematic reviews CRD42016052914. Published data were used. Neither ethical approval nor consent for participation or publication was required.

\section{Patient involvement}

We acknowledge the importance of patient/carer/lay person involvement in research. Although patients/ service users/lay people were not involved directly in the design of this systematic review, the development of the research question was supported and informed by several discussions held by the first author with older adult patient, carer and lay person groups on the subject of modifiable risk factors for dementia. As this was a review of published literature, there are no direct study participants and no opportunity to involve patients/carers or lay people in the development of outcome measures or in recruitment. We have thanked all participants of the contributing studies in the acknowledgements section and will be disseminating results to both lay and scientific audiences via presentations, publications and international dementia organisations.

\section{RESULTS}

The main systematic literature search resulted in 8916 records for review. The two supplementary focused electronic searches yielded 970 and 2870 records (supplementary text 1 shows all search strategies). A further 10 references were identified from reference lists and expert recommendation. Abstract review resulted in 101 records retained for full-text evaluation (figure 1). Seventy-nine records were excluded: 8 because it was unclear whether the sample populations had been free of cognitive decline at baseline ${ }^{9-16} 9$ due to a lack of appropriate cognitive outcomes, ${ }^{17-25} 49$ due to a lack of appropriate risk factor data, combining modifiable and non-modifiable risk factors or where risk factor relationships were not evaluated. ${ }^{26-74}$ Eleven were not longitudinal ${ }^{75-85}$; one was a review article ${ }^{86}$ and one a commentary. ${ }^{87}$ Twenty-two articles relating to 18 cohort studies were included in the review. ${ }^{88-109}$ There were two studies with multiple publications: the Whitehall II study ${ }^{106}{ }^{107}$ and the Washington Heights Ageing Project. ${ }^{89} 9497$ The articles differed in inclusion of risk factors, outcomes and analysis methods and so all were reported in the narrative results. Six studies reported risk ratios for risk factor exposure and incident dementia or Alzheimer's disease (AD) allowing meta-analyses. 88899398100101

\section{Study characteristics}

The included studies totalled over 40000 individuals recruited from high-income countries: the USA, ${ }^{88-97}$ Sweden, ${ }^{98-100}$ Finland,${ }^{101}$ theNetherlands, ${ }^{102103}$ Germany, ${ }^{104}$ France, ${ }^{105}$ the UK, ${ }^{106}{ }^{107}$ Australia ${ }^{108}$ and Korea ${ }^{109}$ (table 1). Study sample sizes ranged from $322^{102}$ to $8845{ }^{93}$ Two studies recruited only men ${ }^{88} 98$ and for five articles, $>50 \%$ of the participants were male. ${ }^{95} 102103106107$ There were no female-only studies. Study follow-up varied from 22 months $^{92}$ to over 20 years. ${ }^{88} 909396101$ Detailed comparison of follow-up is difficult, as different articles provided the information in differing ways. However, a broad categorisation can be made into very short follow-up, estimated at $<5$ years, ${ }^{92} 109$ short follow-up, estimated at $>5-10$ years, ${ }^{89} 949599100104106108$ moderate follow-up, estimated at >10-20 years ${ }^{91} 9798102103105107$ and long follow-up, estimated at $>20$ years. ${ }^{88} 909396101$ There were 12 articles where baseline measures were taken in midlife ( $>40$ and $\leq 65$ years) $)^{8893969899101-103105-108}$ and 9 articles where the baseline was in late life (>65 years). 899192949597100104109 One study included those in earlier adult life with baseline age $\sim 26$ years. ${ }^{90}$

\section{Cognitive outcomes}

Eight manuscripts reported on dementia outcomes using standard diagnostic criteria, ${ }^{88} 89959798100101{ }^{103} 2$ used a dementia diagnosis made as part of medical treatment but did not give details of diagnostic criteria, ${ }^{93}{ }^{104} 5$ reported results specifically for $\mathrm{AD}^{88} 899798100$ and 12 reported on non-dementia cognitive outcomes. Cognitive measures included use of a screening test ${ }^{92} 109$ or a neuropsychological battery. ${ }^{91} 949699102105-108$ See table 2 for details of the diagnostic criteria and assessment tools used by each study.

\section{Risk factor measurement}

Articles varied in their selection of risk factors and the risk factors varied in number (from 2 to 13) and definition. See table 1 and online supplementary table 1 for details of risk factors included in each study and the cutpoints used to define presence of risk factors. Substantial overlap was identified for coverage of risk factors between studies; the most commonly included risk factors being smoking and hypertension or high blood pressure, although no single risk factor was common to all studies (table 1).

Different analyses aggregated risk factors or unhealthy behaviours or protective factors or healthy behaviours in different ways (table 2). Three used some form of clustering, cluster analysis, latent factors or principal component analysis and examined the relationship between membership of each cluster and cognitive outcome, ${ }^{9599} 105$ 15 studies categorised each risk factor as present or absent ( 1 or 0$)$ and then generated a variable which was the total number of risk factors present. ${ }^{88-94} 9698100101104107-109$ Three elaborated further by creating a weighted risk 


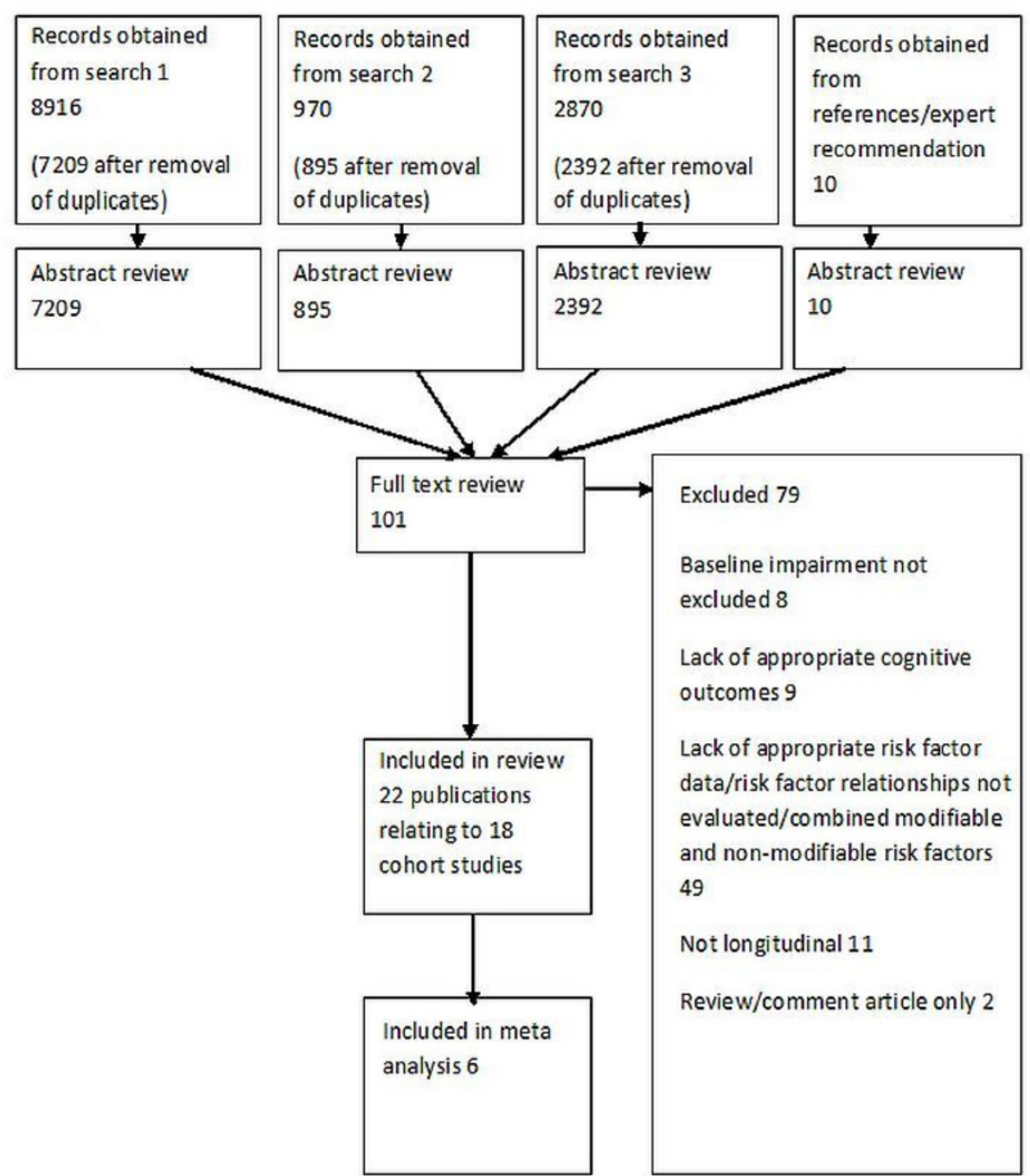

Figure 1 Preferred Reporting Items for Systematic Reviews and Meta-Analyses flow chart detailing the number of records included at each stage of the review.

score $^{97102103}$ and one used categories to combine two risk factors (alcohol and smoking) to examine additive impact. ${ }^{106}$

In general, studies used either linear, logistic or Cox proportional hazard regression (tables 2 and 3 ) to examine the relationship between baseline risk and cognitive outcomes; one study used latent growth curves $^{106}$ and one provided graphical results only. ${ }^{96}$ Five studies looked at the inverse of risk factors and reported on protective or ideal health behaviours.90 9197104109 Most studies adjusted for age, sex and education and/ or socioeconomic status (tables 2 and 3); one adjusted for age and sex only ${ }^{102}$; one for sex only ${ }^{91}$; one for patterns of test completion and sex and in one case no information on the method of covariate adjustment was provided. $^{96}$
Association between risk factors and cognitive outcomes and/ or dementia

Study findings showed remarkable similarity with the majority reporting a relationship between exposure to increased risk factor load and subsequent poorer cognitive function or dementia (table 3). No clear differences of results were observed by baseline age group, that is, cohorts in midlife or late-life at baseline, or for length of follow-up, although the varied presentation of study results meant that formal statistical testing could not be performed.

Eleven articles reported a relationship between risk factors and cognitive outcomes 8899929396 98-103; three between unhealthy behaviours ${ }^{105-107}$ and poorer cognitive outcomes; three reported a relationship between protective factors $^{97104109}$ and two between ideal health 


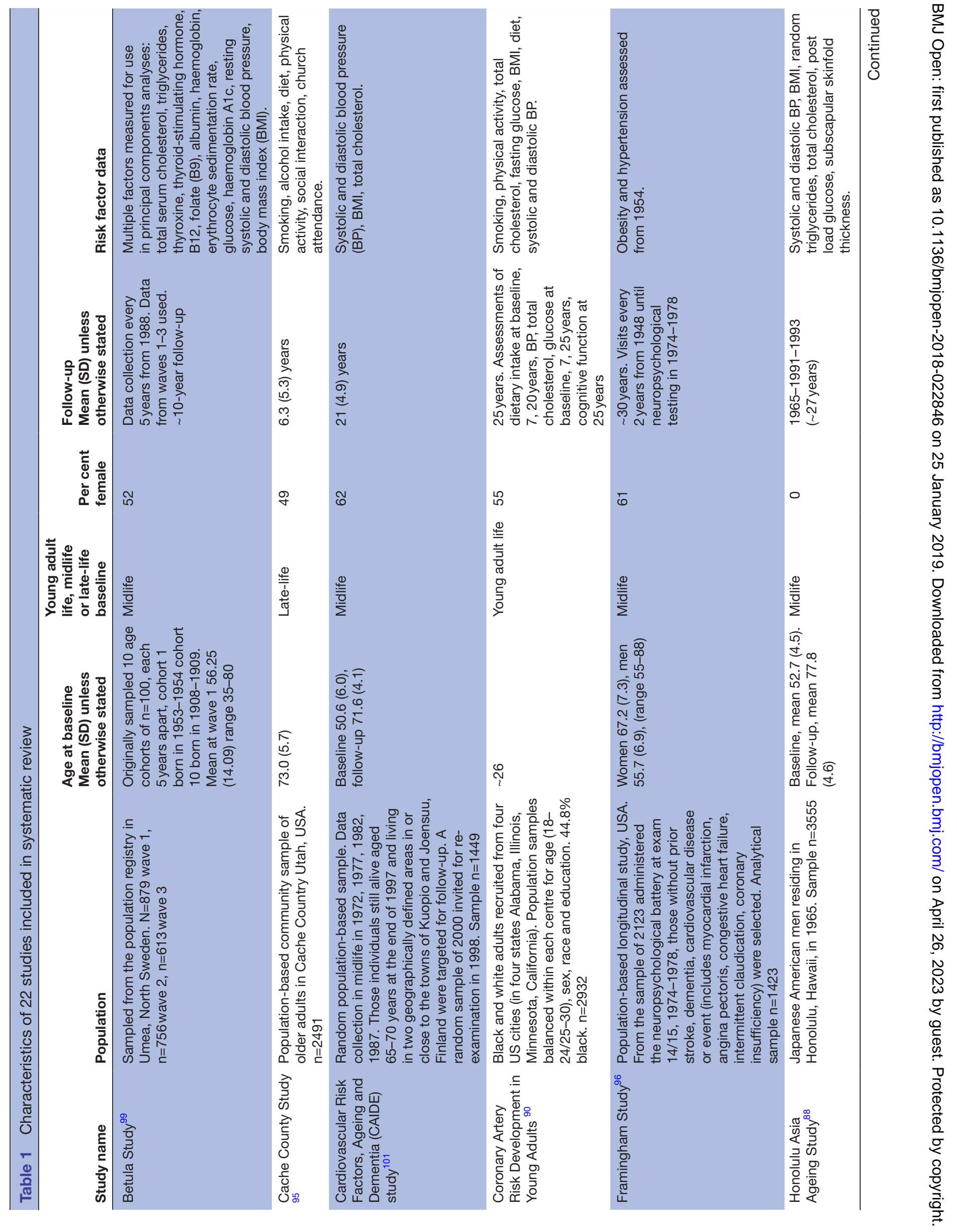




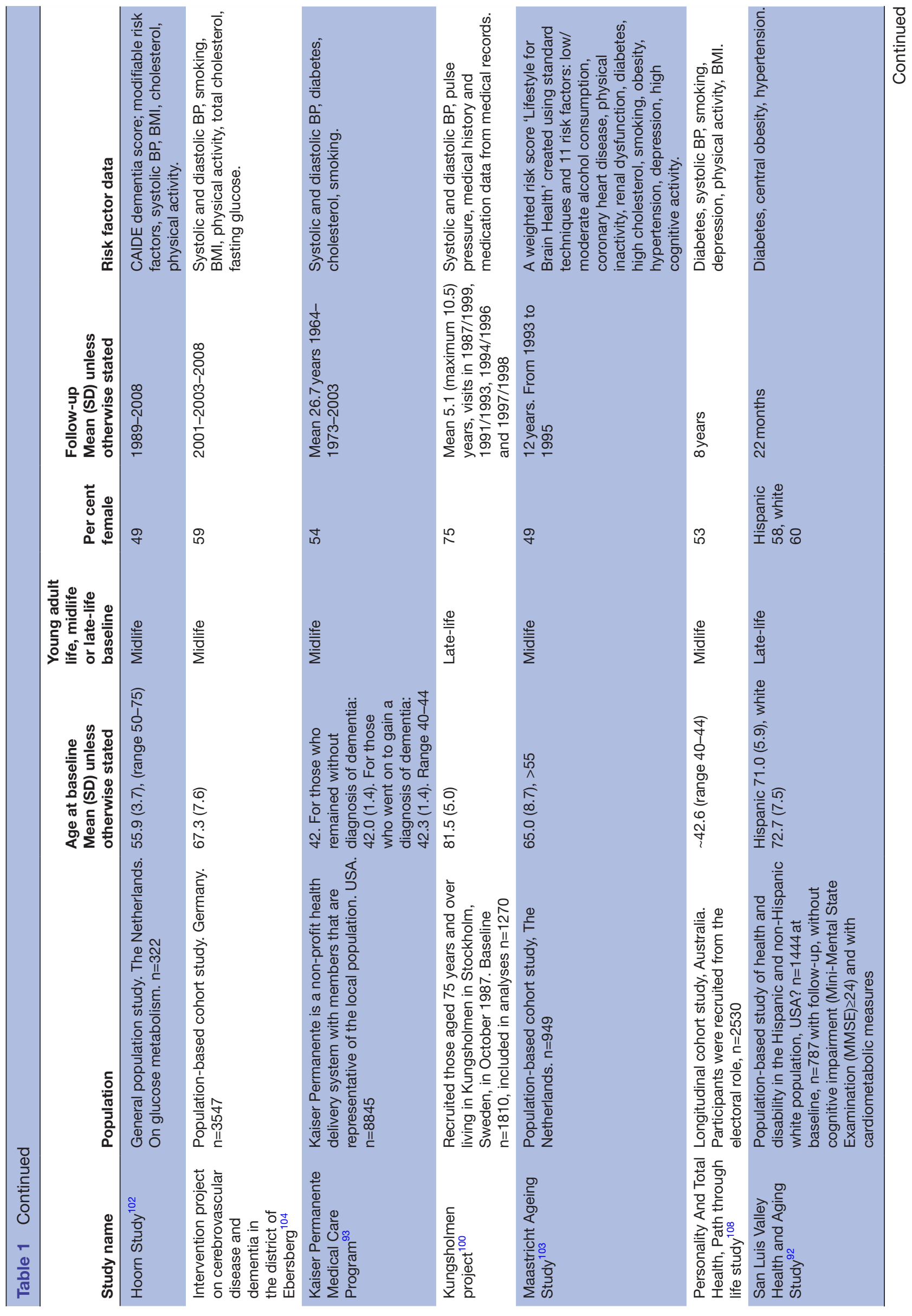

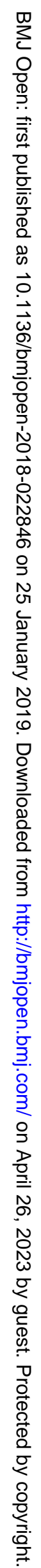




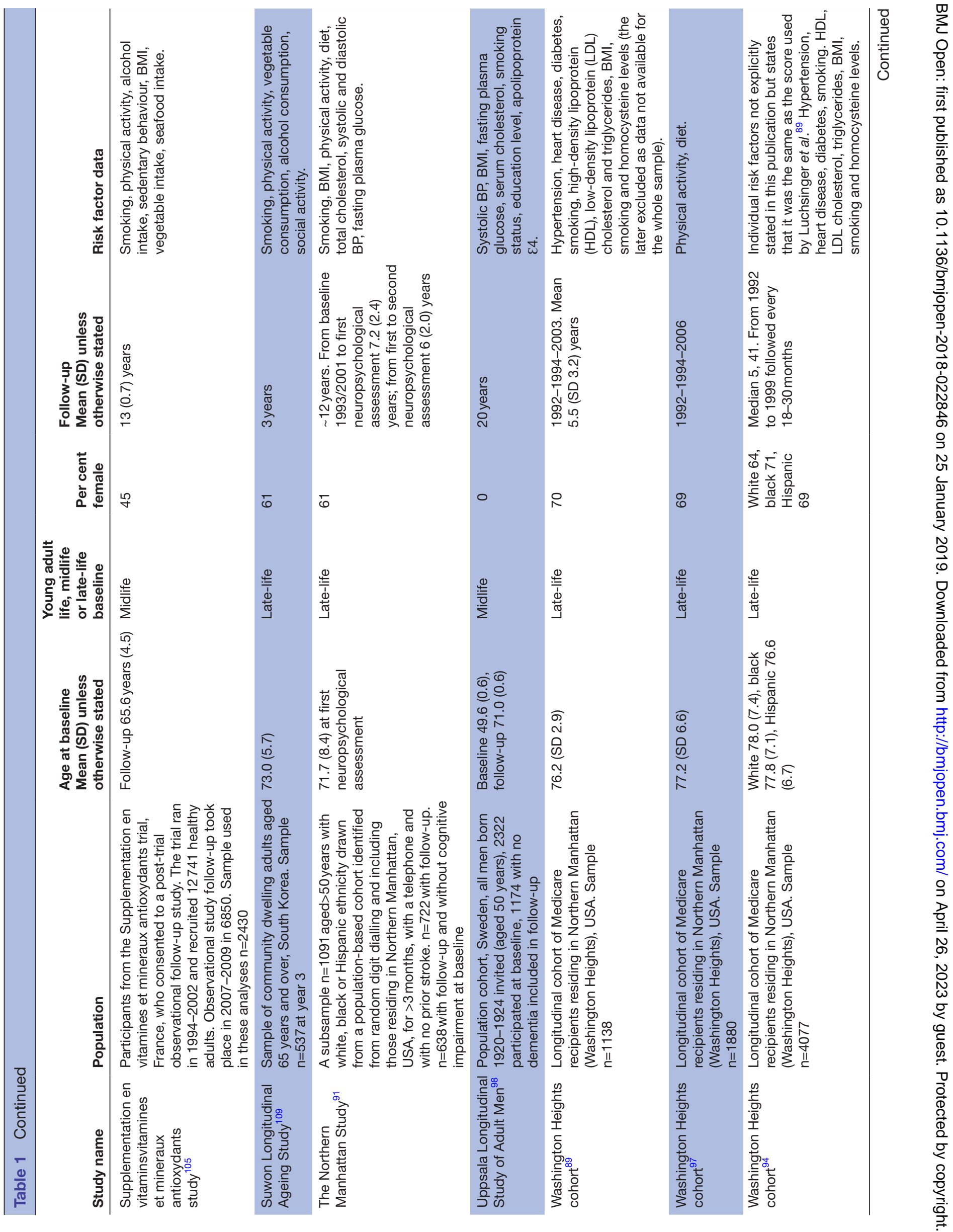


behaviours ${ }^{9091}$ and better cognitive outcomes at follow-up. For the remaining studies, that is, those that reported a more mixed relationship between risk factor exposure and increased risk, the Personality and Total Health study found that only reaction time showed a relationship between risk factors and cognitive outcomes ${ }^{108}$; for the Schneider et al analyses of the Washington Heights study, risk factors were only associated with a small attenuation in decline in memory measures in black participants ${ }^{94}$ and in the Cache Country study, the unhealthy behaviours plus religious belief cluster showed an increased risk of dementia, while the unhealthy behaviour, non-religious group and the healthy behaviour groups did not. ${ }^{95}$ In addition to the Cache County study, two further studies examined the relationship between groups of co-occurring risk factors. The Supplementation en vitamines et mineraux antioxy dants study study reported that their unhealthy lifestyle latent factor was associated with poorer memory but not with executive function and that the main drivers for this association were low fruit and vegetable consumption and low physical activity. ${ }^{105}$ The Betula Study found that varying clusters of health components (metabolic, glycaemic, lipid, thyroid, inflammatory and nutritional clusters) had varying relationships with differing cognitive abilities with the metabolic component showing the strongest relationships ${ }^{99}$ (table 3 ).

Finally, results were essentially consistent across the studies with more than one publication. The Whitehall study found a relationship between increased risk factor exposure and different measures of cognitive decline using both latent growth curve ${ }^{106}$ and logistic regression analyses ${ }^{107}$; the Washington Heights study reported an increased risk of incident $\mathrm{AD}^{89}$ with greater numbers of risk factors and a lower risk of incident $\mathrm{AD}$ with greater health behaviours (diet and physical activity). ${ }^{97}$

Six studies provided various risk ratios for the impact of one, two or three or more risk factors; five for incident dementia ${ }^{889398100101}$ (figure 2 and online supplementary text 2 show results of each meta-analysis) and three for $\mathrm{AD}$ (online supplementary figure 1). ${ }^{89}{ }^{98} 100$ Forest plots of these showed a clear dose response such that higher numbers of risk factors were associated with an increased risk. Based on the rare disease assumption, ${ }^{110}$ RRs, ORs and HRs were combined in two separate meta-analyses, one for dementia and the other for $\mathrm{AD}$, yielding pooled ratios for presence of one, two and three or more risk factors compared with no risk factors. A fixed effects meta-analysis was used because the number of studies was small preventing a good estimate of the between study variance, however for comparability results are also reported for a random effects model. See online supplementary text 2 for details of the meta-analyses. For dementia outcomes fixed effect pooled risk ratios for one risk factor were 1.2 (95\% CI 1.0 to 1.4), for two risk factors 1.7 (95\% CI 1.4 to 1.9) and for three or more risk factors 2.2 (95\% CI 1.8 to 2.7) ${ }^{889398100101}$ Results for the random effects model did not differ. Heterogeneity was low and there was no evidence of publication bias (online 


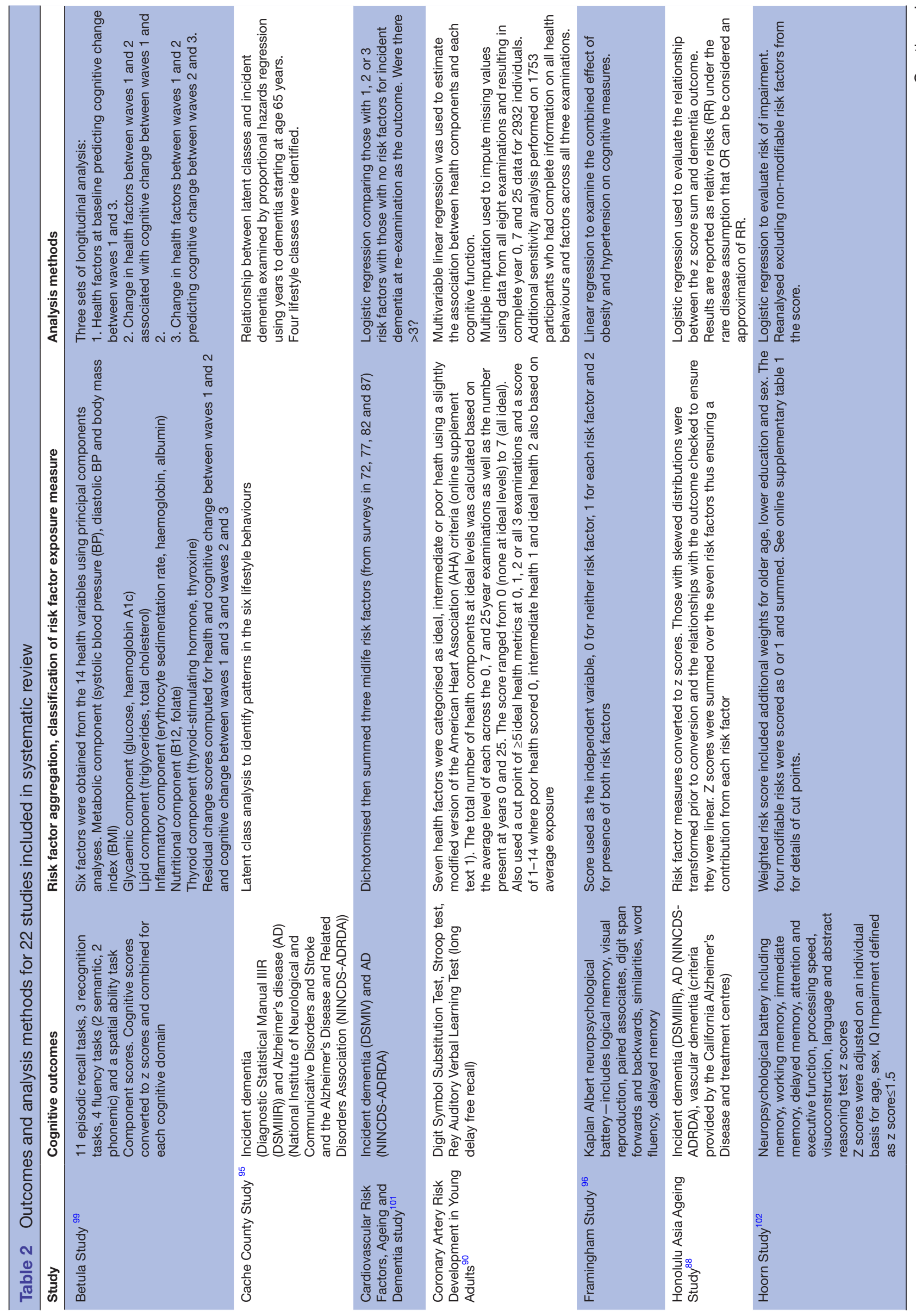

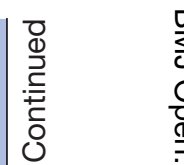




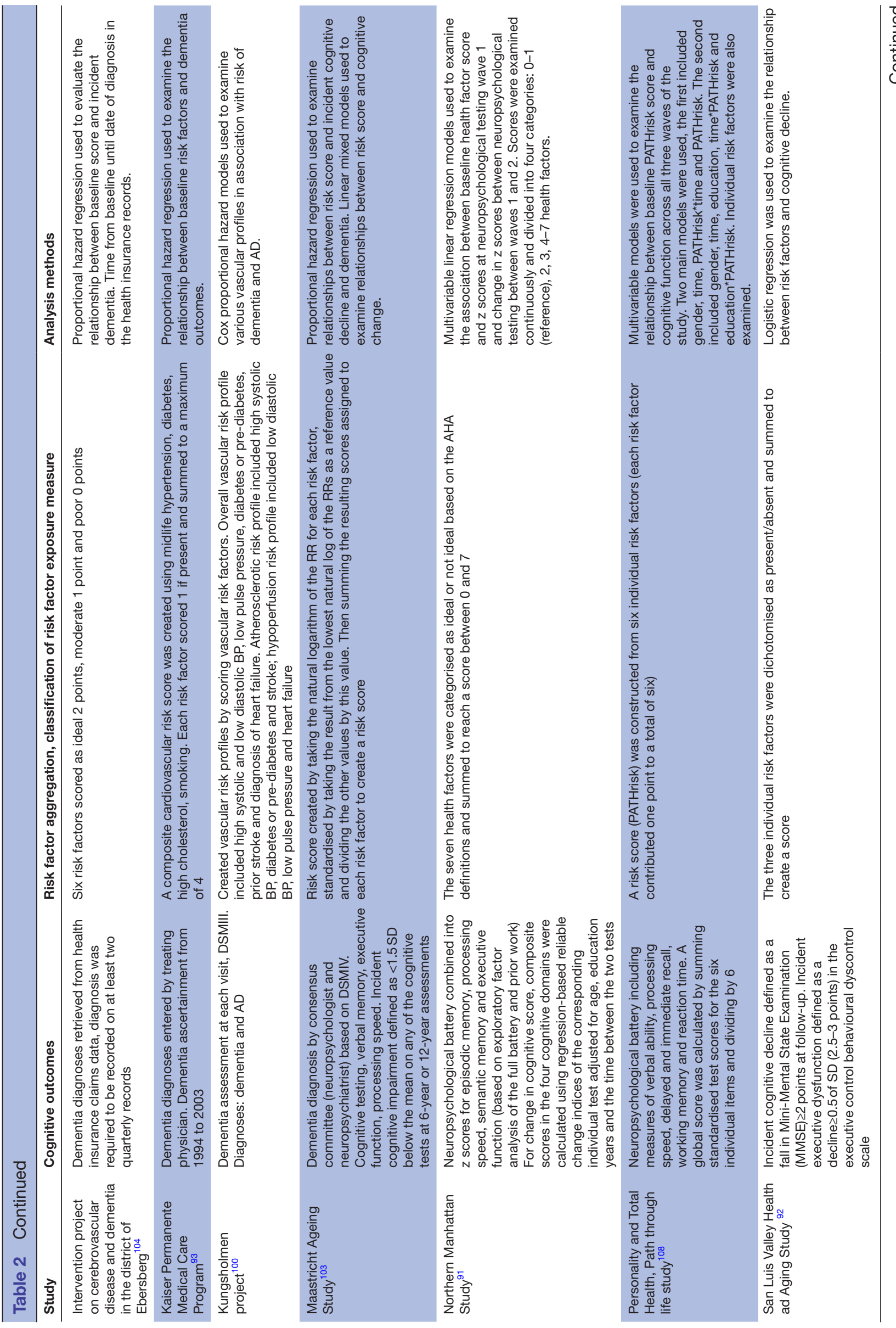

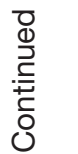




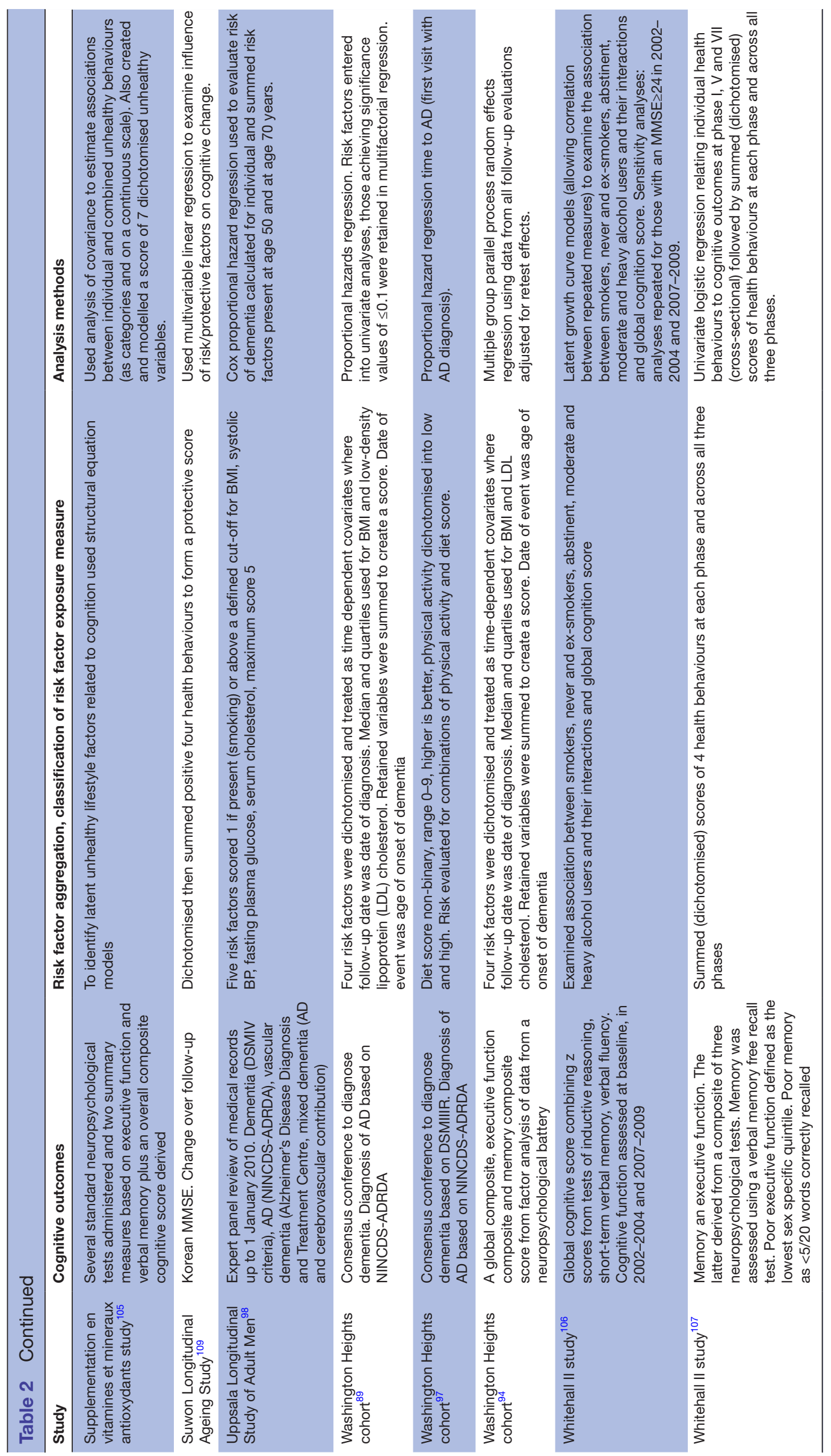




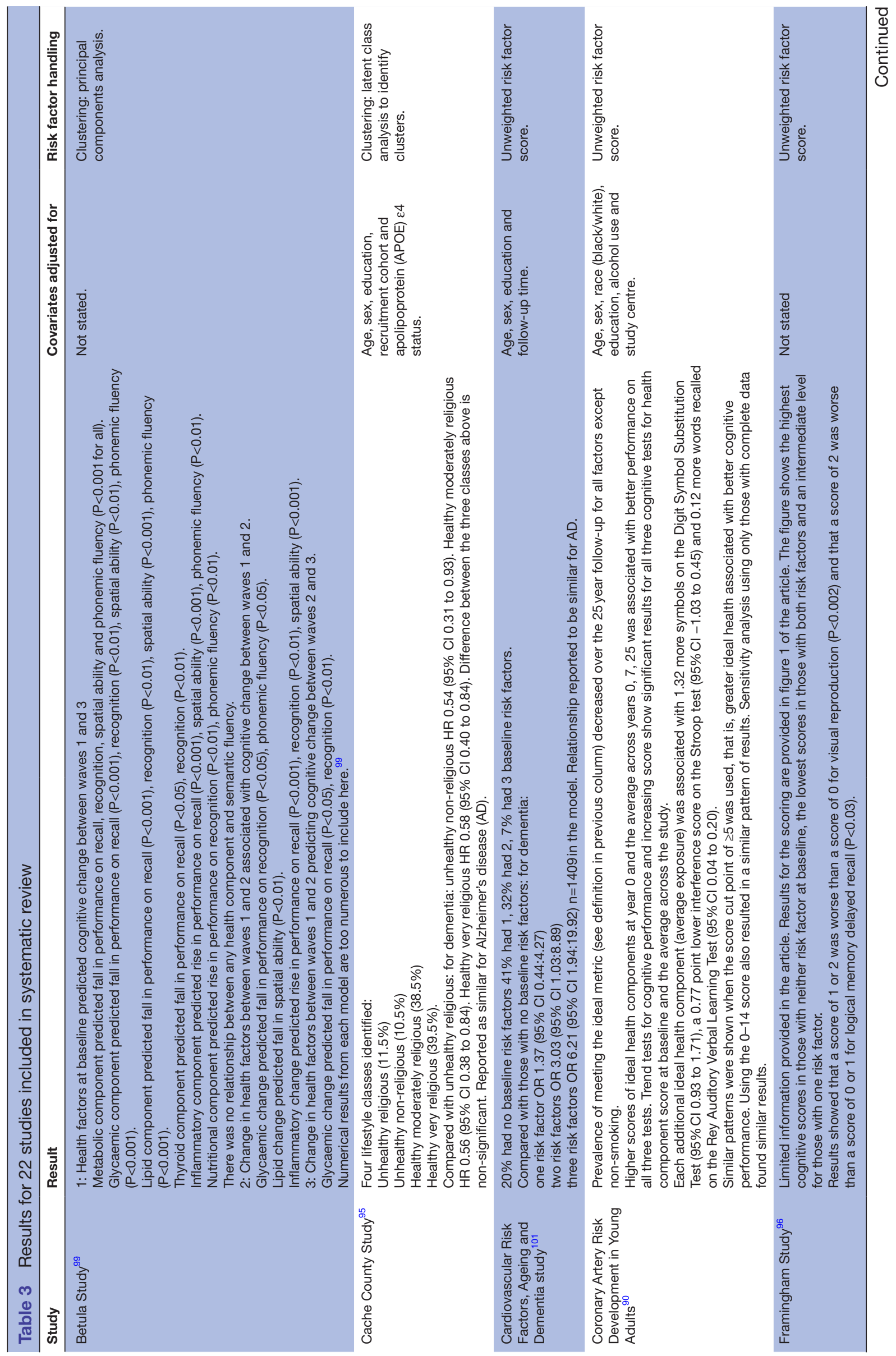




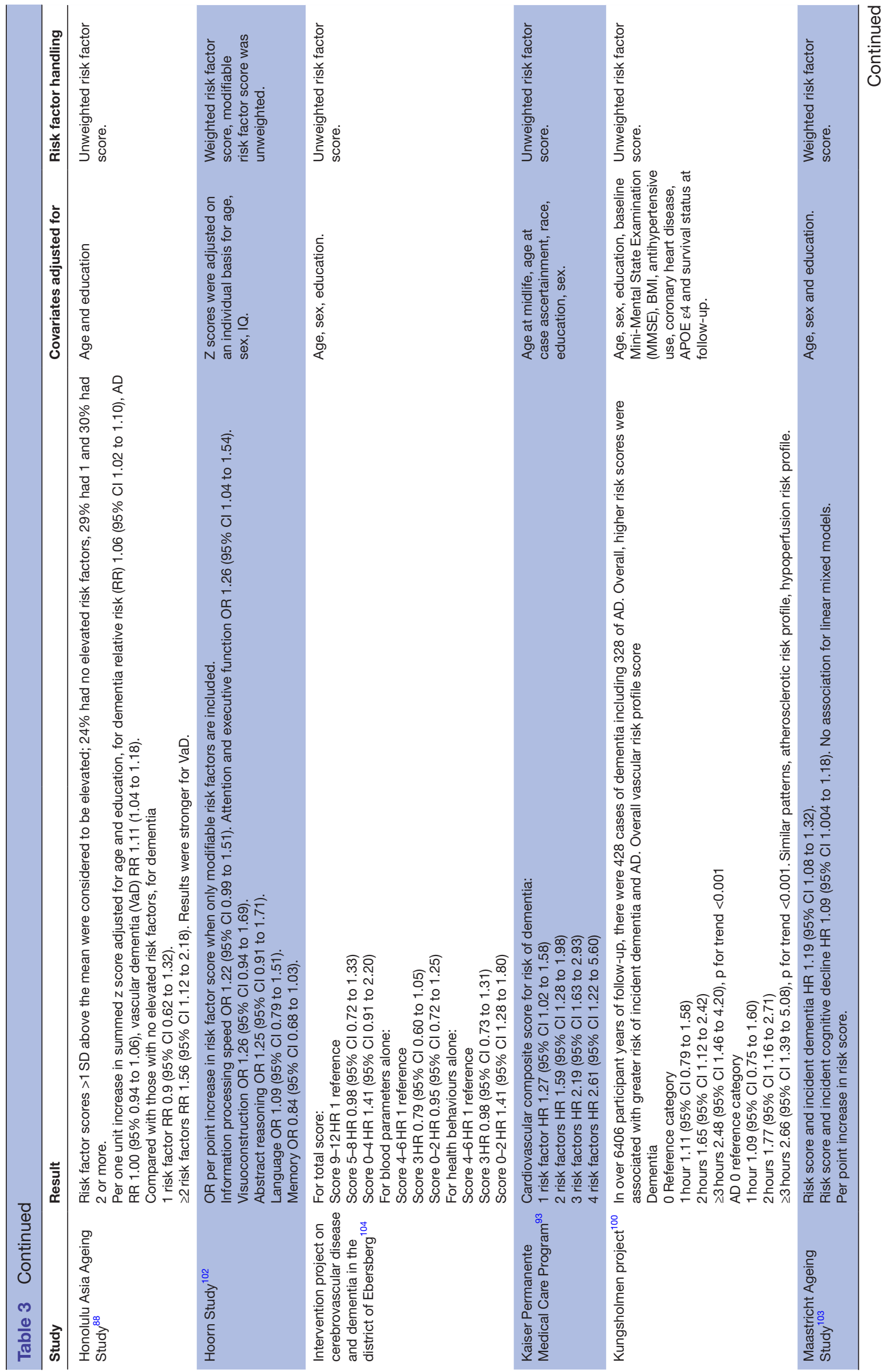




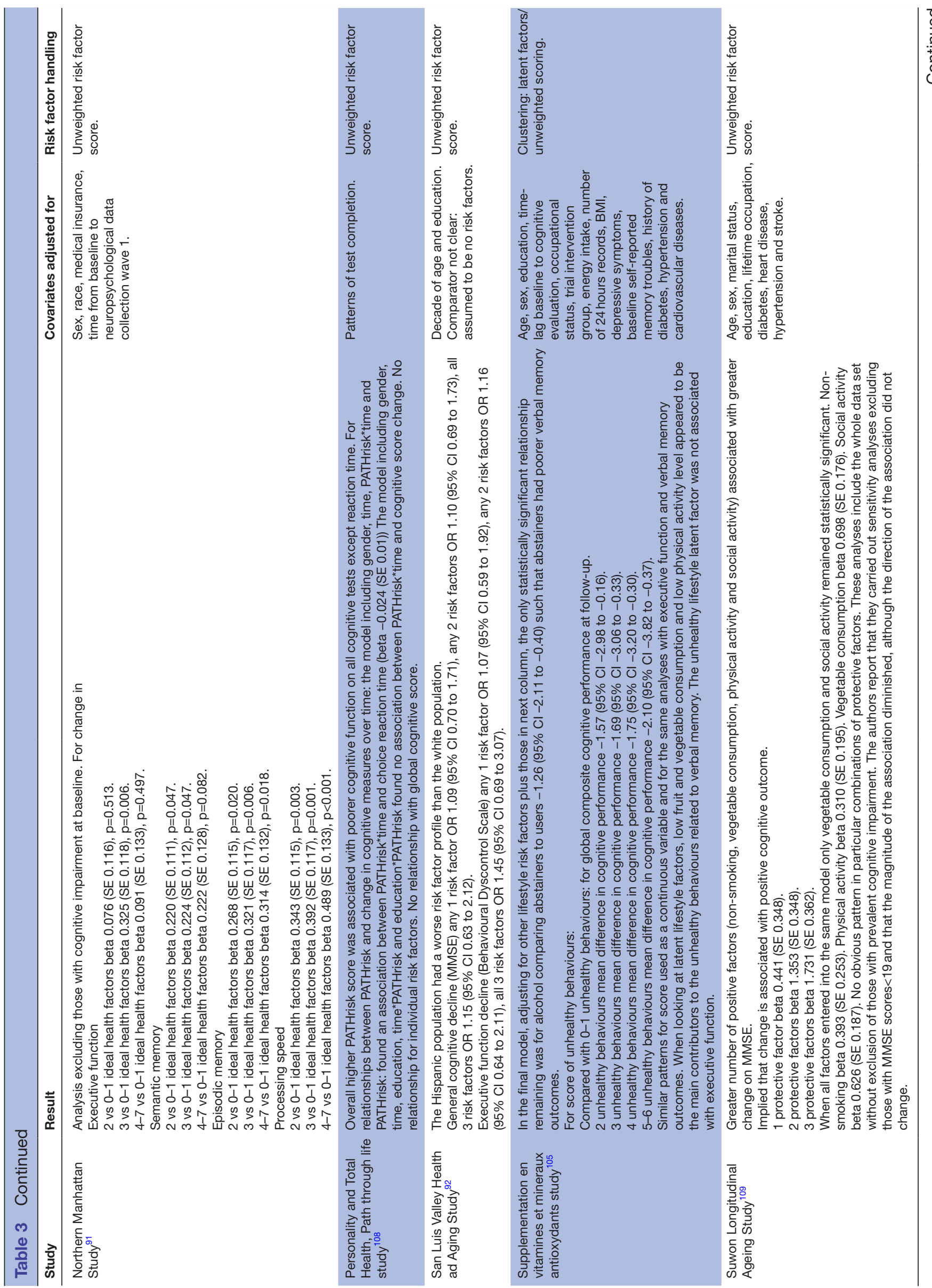




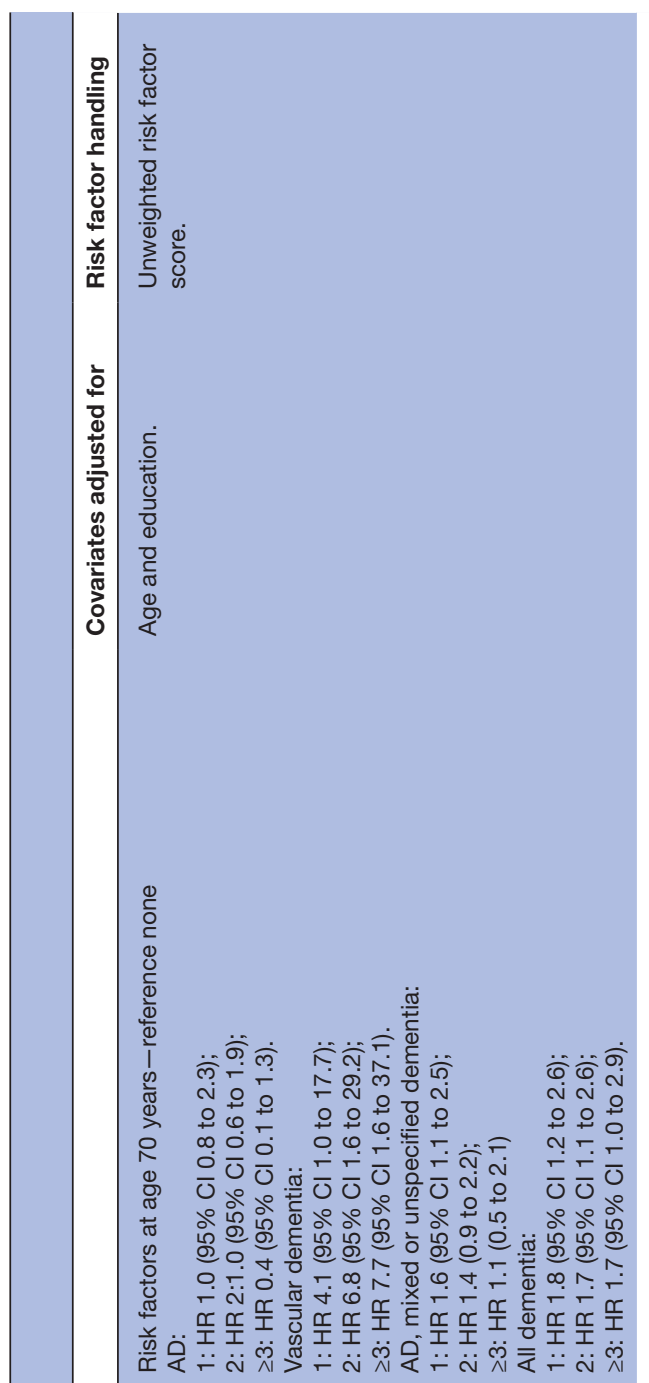

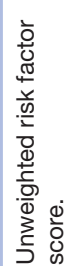

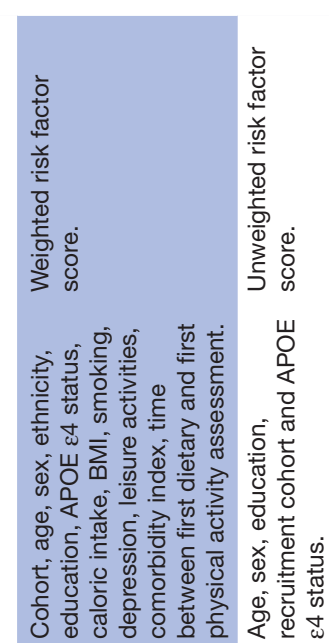

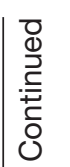

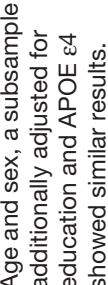

is 它怘

造

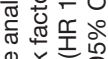

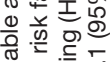

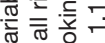

旅

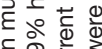

잉

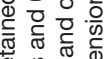

은

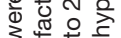

은 훈

किष

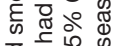

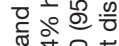

ه

舫

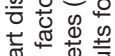

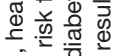

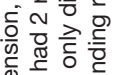

क्षे 웅 훙

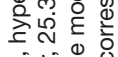

究

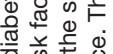

需

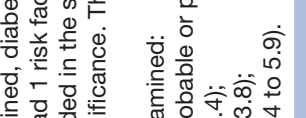

宔

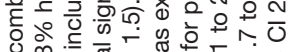

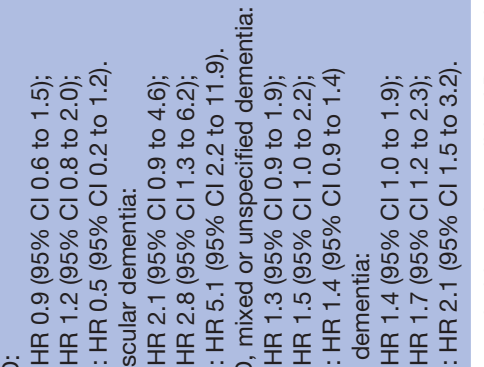

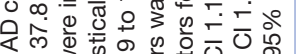

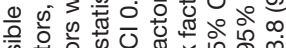

of

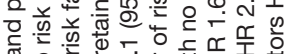

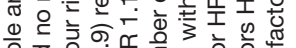

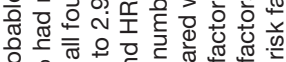

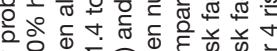

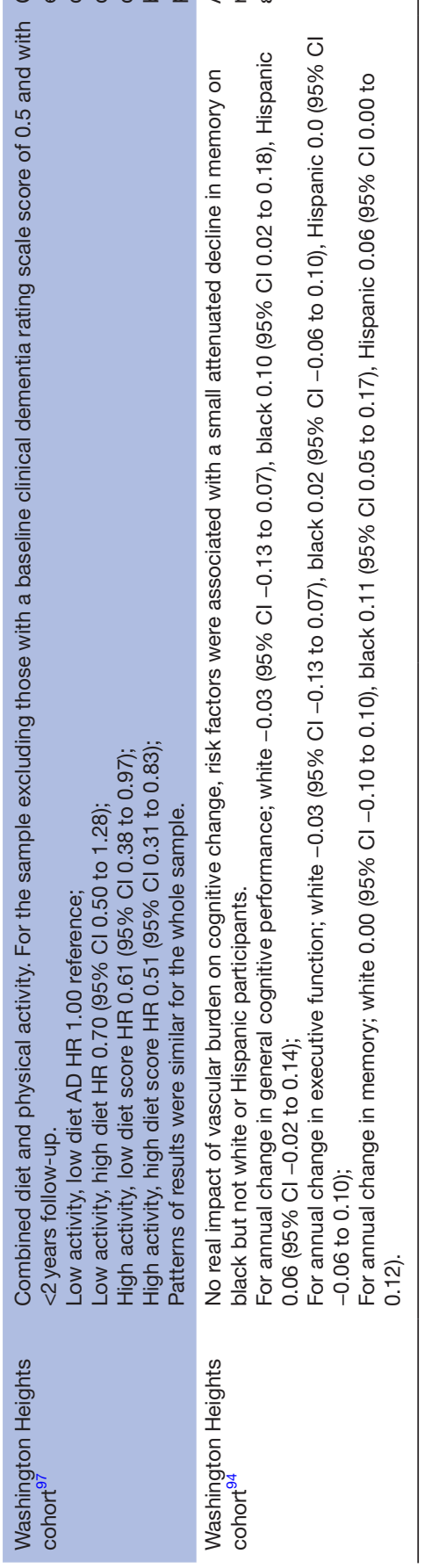




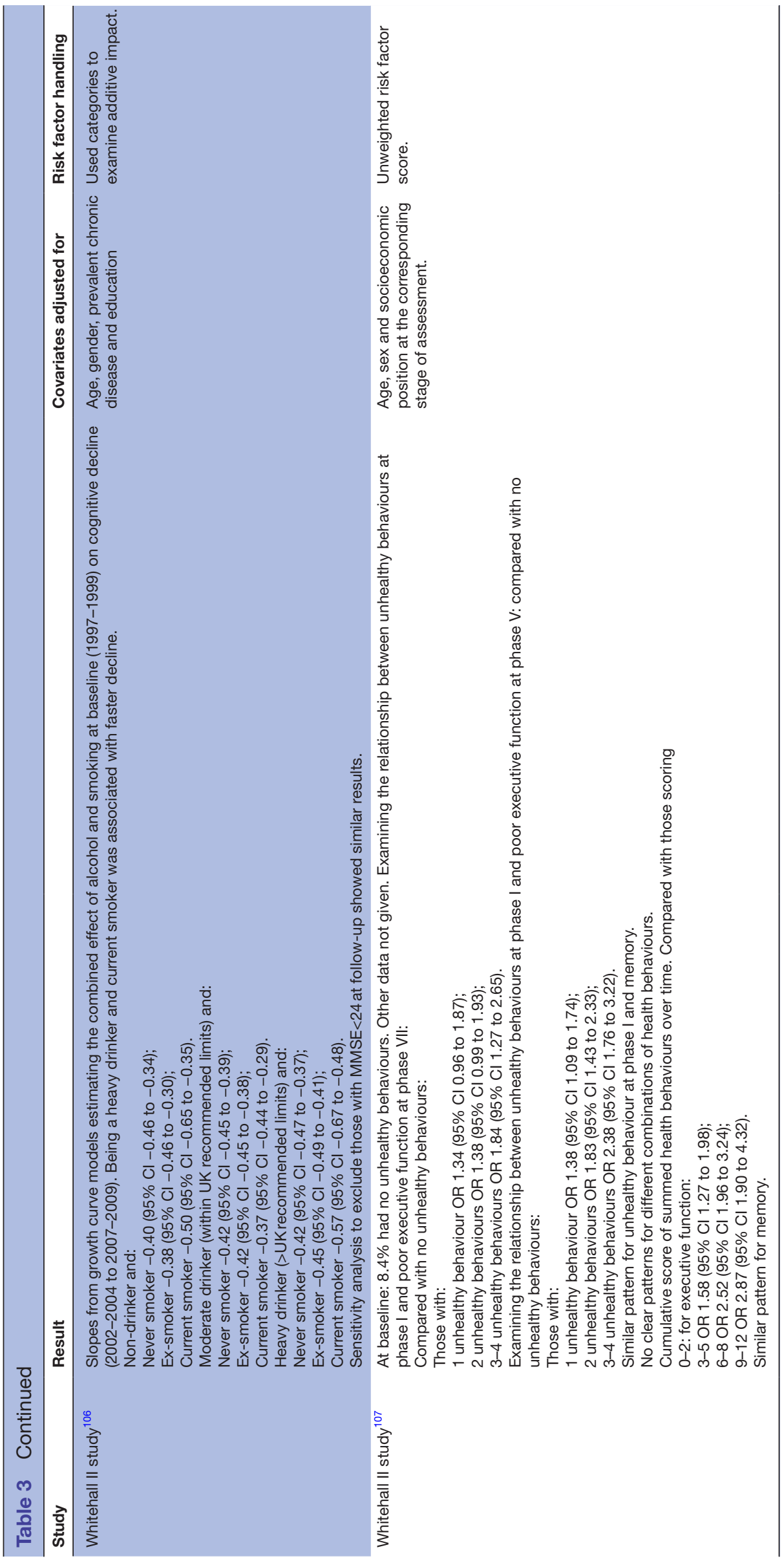




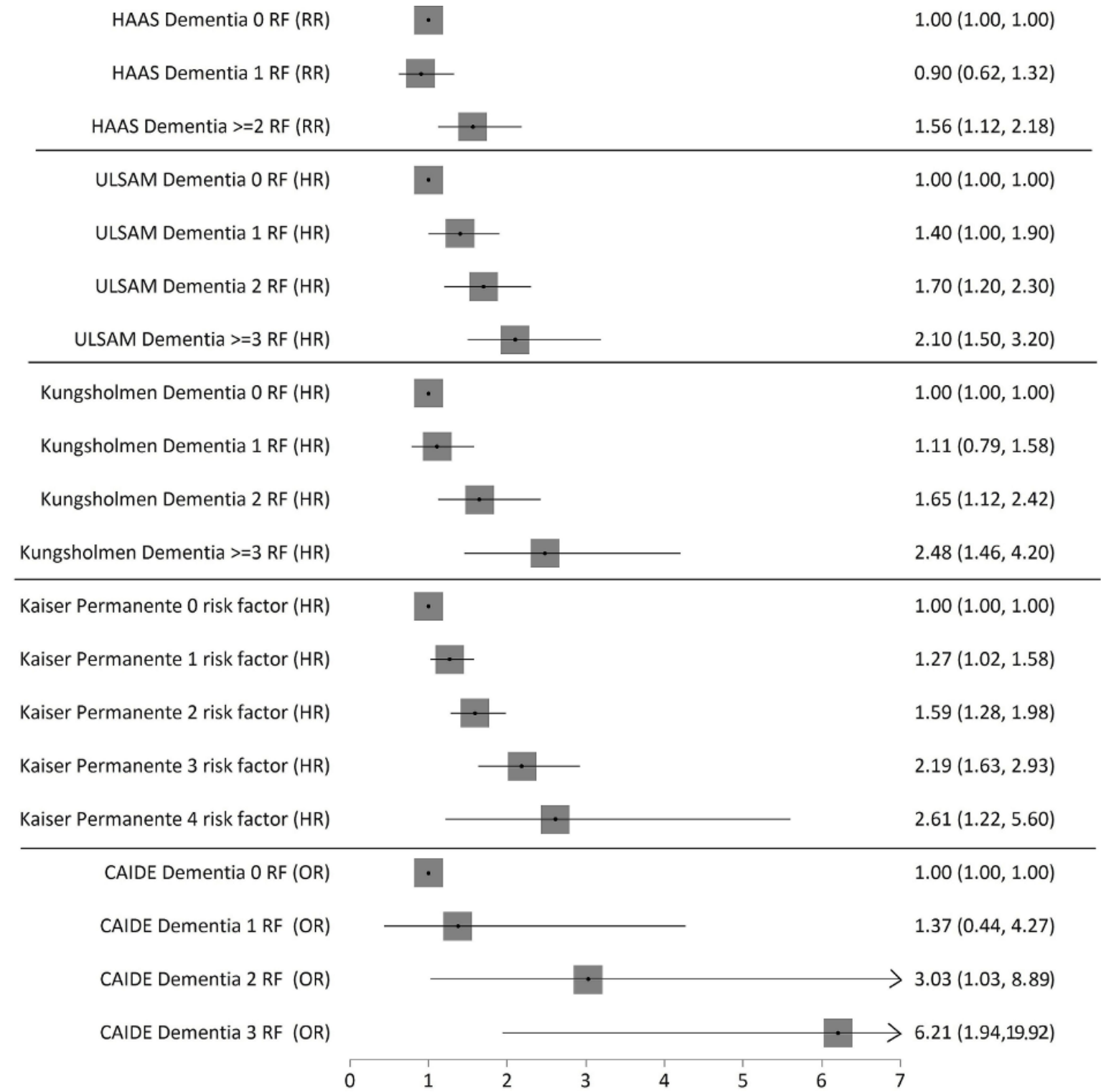

Figure 2 Forest plots showing dose response for exposure to increasing numbers of risk factors and risk of incident dementia for individual studies Follow-up 27 years for the Honolulu Asia Ageing Study (HAAS) cohort, 20years for the Uppsala cohort, 5years for the Kungsholmen cohort, 26.7 for the Kaiser Permanente cohort and 21 years for the Cardiovascular Risk factors Ageing and Dementia (CAIDE) cohort. RF, risk factor; RR, relative risk.

supplementary text 2). For $\mathrm{AD},{ }^{89} 98100$ fixed effect pooled risk ratios for one risk factor were 1.2 (95\% CI 0.9 to 1.5 ), for two risk factors 1.8 (95\% CI 1.4 to 2.3 ) and for three or more risk factors $1.2(95 \%$ CI 0.2 to 6.1$)$. The results for the random effects model were 1.2 (95\% CI 0.9 to 1.6) for one risk factor, 1.8 (95\% CI 1.2 to 2.8) for two risk factors and 1.5 (95\% CI 0.9 to 2.5) for three or more risk factors. For $\mathrm{AD}$, the heterogeneity was high and the number of constituent studies was low, restricting analysis of publication bias (online supplementary text 2). Visual examination of the plotted results per incremental risk factor for the studies included in the meta-analysis showed no clear pattern by study baseline age, population sex distribution, length of follow-up or study covariates; however, the small numbers precluded meta-regression or other formal statistical testing.

\section{Study quality}

Of the 22 articles, 14 were assessed as having an overall medium risk of bias $88929395969899101102104-107109$; 7 as having a low risk ${ }^{89} 909497100103108$ and 1 as having high risk. ${ }^{91}$ Risk of bias was assessed with regard to recruitment, exposure (eg, assessments of risk factor exposure), outcome (eg, assessment tools, use of blinded assessors) and follow-up (eg, attrition, length of follow-up) (online supplementary table 2). Several studies analysed population-based cohorts, ${ }^{89}$ 92-97 99-103108 109 some specifying that their analyses were based on selective populations. ${ }^{90} 91959698101102105$ Two studies were specifically designed to recruit selective populations; the Honolulu Asia Ageing Study which only included Japanese American men living in Honolulu ${ }^{88}$ and the Whitehall study which recruited exclusively from a civil servant population. ${ }^{106} 107$ Two further studies 
recruited from previously existing healthcare provider or insurance databases. ${ }^{93} 104$ All studies used recognised and standard measures to characterise baseline risk factors, although variation in the evidence base, current guidelines and recommendations at the time of study data collection and analysis inevitably resulted in diverse risk factor definitions.

Regarding outcome measurement and length of follow-up, two studies reported follow-up likely to be <5years, putting them at risk of reverse causality $^{92}{ }^{109}$; however, five studies reported long (ie, $>20$ years) follow-up 88909396101 and three of these reported incident dementia outcomes. ${ }^{88} 93101$ Two studies used dementia outcomes taken from medical databases, ${ }^{93} 104$ which may have underestimated the number of cases, but all other studies used standard diagnostic criteria or standard neuropsychological tests. The majority of studies reported on incident dementia or on change in cognitive function assessed using neuropsychological tests; however, five studies reported cognitive function only at follow-up, potentially including prevalent, rather than incident, cases of poor function. ${ }^{90} 96102105107$ The majority of studies adjusted for age, sex and education, although some carried out further adjustment for wider covariates. Finally, details of how researchers had accounted for missing data and attrition were not consistently reported with information provided in around half the articles. ${ }^{90} 9294969799100$ 105-108

\section{DISCUSSION}

This systematic review of the evidence base relating to intraindividual co-occurring modifiable risk factors for dementia and cognitive decline found a clear relationship between the presence of/exposure to greater numbers of baseline risk factors and an increased risk of later cognitive decline or incident dementia. The converse was also seen in identifying a relationship between greater numbers of protective factors or healthy behaviours and a reduced risk of cognitive decline or dementia.

Studies reporting risk ratios for all-cause dementia per incremental risk factor consistently demonstrated a clear dose-response relationship. When combined in a meta-analysis, a $20 \%$ increase in dementia risk with the presence of one risk factor (combined risk ratio $1.2(95 \%$ CI 1.0 to 1.4)) was observed rising to $65 \%$ for two risk factors (1.7 (95\% CI 1.4 to 1.9)). Presence of three risk factors doubled the risk of dementia with a combined risk ratio of 2.2 (95\% CI 1.8 to 2.7). Fewer studies and incident cases were identified for a similar meta-analysis of $\mathrm{AD}$ with the dose response only being evident for the presence of one and two risk factors.

Although data relating to summed risk or protective factors showed clear relationships with cognitive outcomes, limited data were available on clustering of specific risk factors and subsequent cognitive outcomes. Only three studies used statistical clustering techniques and the methods are too diverse and the results too varied to allow conclusions to be drawn.

To our knowledge, this is the first review to examine the impact of intraindividual co-occurring modifiable risk factors and risk of dementia and cognitive decline. As such, comparison to prior similar work in this area is difficult, however, scoring systems involving the sum, or weighted sum of individual risk factors, including both modifiable and non-modifiable risk factors, have been widely used in other areas such as cancer, ${ }^{111}$ all-cause mortality ${ }^{112}$ and, especially, cardiovascular disease. ${ }^{113} \mathrm{~A}$ recent systematic review reported on 363 such cardiovascular disease risk scores or models ${ }^{114}$ and several such cardiovascular and other scores have also been used to predict dementia outcomes. ${ }^{46}$ Our findings are congruent with such scoring systems and are biologically plausible with higher numbers of vascular risk factors in midlife associated with elevated amyloid deposition in addition to vascular damage. ${ }^{115}$ What our findings add is the first quantifiable estimation of the impact of risk factor accrual. What we were unable to add is evidence related to particular risk factor clusters. In fact, data on the impact of modifiable risk factor clusters are rare, although recent work on all-cause mortality found that combinations of specific risk factors, for example, physical inactivity, prolonged sitting and short or long sleep duration are associated with higher levels of mortality risk. ${ }^{112}$

\section{Limitations}

Our review is inevitably limited by its exclusive dependence on published results. This meant that we were unable to: i) statistically evaluate trends within individual studies, ii) evaluate the impact of additional covariates, iii) evaluate the impact of particular population characteristics or iv) the potential for particular risk factors having a greater or lesser impact. We were also unable to explore the relationship between specific risk factor clusters or between greater risk factor burden and cognition beyond that assessed by the included studies and there was considerable variability in the modifiable risk factors addressed in each study (online supplementary table 1), thus limiting the opportunity for unpicking individual factor impact. A further limitation relates to restricting inclusion to known and widely accepted modifiable risk factors. While this makes findings more amenable to public health dissemination, it may omit important unknown or emerging modifiable risk factors, such as air pollution. ${ }^{116117}$ Furthermore, despite not being amenable to intervention and therefore not the focus of this review non-modifiable risk factors also undoubtedly play a role. The use of a binary classification for risk or protective factors, while clinically practical, may also have resulted in a loss of subtlety, particularly since definitions of risk differed across studies. Risk factors are also associated with participant attrition and few studies took this into account in modelling. Furthermore, few papers considered potential treatment effects. Finally, although we concentrated 
on adulthood, emerging evidence is suggesting a potential role for accrual of exposure to vascular risk factors in childhood and poorer cognition in midlife. ${ }^{118}$

Inevitably results drawn from longitudinal cohort studies are subject to bias, and, as is often the case in systematic reviews, the length of follow-up, assessment of outcomes and use of covariates varied. The strength of the evidence also needs to take into account the two studies contributing more than one analysis. Furthermore, generalisability may also be limited since the study populations were drawn exclusively from high-income countries and, as such, may reflect a more homogeneous, and potentially more medicated or treated, population than those in low-income and middle-income countries where risk factor prevalence, recognition and treatment rates may differ.

A further consideration in the existing studies is the way in which age is considered beyond its role as a covariate. Age is the most important risk factor for dementia well into the tenth decade ${ }^{119}$ and although not a modifiable risk factor, it is a source of important and thus far poorly understood heterogeneity in risk for many diseases of older age, including dementia. ${ }^{120}$ The role of age, or time, in evaluating duration, as well as presence, of risk factors may be key and so far few studies have examined this. ${ }^{121-126}$ Ageing is associated with widespread processes of deficit accumulation: beginning at molecular and subcellular levels, ${ }^{127}$ and scaling up ${ }^{128}$ to become detectable as biomarkers ${ }^{129}$; then by routine laboratory methods ${ }^{130}$ and then clinically. ${ }^{130}$ In general, the studies of deficit accumulation, in both general samples and in special groups such as people with HIV-AIDS ${ }^{131}$ or intellectual disabilities, ${ }^{132}$ show that any risk factors which are age-related and adverse (eg, associated with mortality) will increase the risk of cognitive decline. This sometimes raises the objection that combining deficits in this manner makes it hard to know which ones are important. The counterargument is that this is not how age-related disease works. Often, many of the factors that in the aggregate are strongly associated with dementia (and which notably reduce the explanatory value of age) are not themselves significantly associated with cognitive decline when considered one at a time. ${ }^{124-126}$ The better remedy is to consider which other factors might mitigate (eg, health protective behaviours) or exacerbate (eg, social vulnerability) the adverse effects of such deficits on cognition. ${ }^{125}$ As this approach is comparatively new-at least in its application to cognitive decline and dementia-there is as yet little to review. Given, however, the recent report from two prospective, community-based autopsy studies, showing that in one-quarter of patients with a history of delirium, accelerated cognitive decline was not related to classical neuropathology suggests that there is much to learn about how late-life dementia is related to overall health. ${ }^{133}$ Such observations encourage widening the scope of investigative approaches.

Notwithstanding these limitations, this is the most comprehensive and, to our knowledge, the first synthesis of evidence on the impact of co-occurring risk factors for dementia. It presents an evidence base that is largely consistent and may imply a potentially very simple relationship such that the higher the number of risk factors to which a person is exposed the greater their risk. The potential for a causal relationship is supported by the consistent finding across studies, the use of population-based samples although with some inevitable risk of bias, the longitudinal nature of the data, the suggestion of a dose-response relationship and the strength of the association between the summed risk factors. Further research is required to determine whether particular combinations of risk factors have greater impacts on cognitive function than others, which clinical thresholds should be used to classify risk or whether relationships differ in different population groups, for example, at extreme age. More understanding is also needed for the relationship between modifiable and non-modifiable factors and risk factor combinations, not least to stratify population subgroups and identify those at highest risk. Currently, the best course of action for both individuals and health organisations would be to seek to keep modifiable risk factor exposure to a minimum and to prevent exposure to further risk factors. The current findings support the use of risk indices for screening those at high risk of dementia and indicated for intervention.

\section{CONCLUSIONS}

The evidence relating to the impact of co-occurring, within individual, risk factors and the risk of cognitive decline or dementia is highly consistent. It demonstrates that greater numbers of risk factors are associated with worse cognitive outcomes and greater numbers of protective factors with better cognitive outcomes. We provide quantitative evidence of a dose response such that one risk factor is associated with an $20 \%$ increase in risk of incident dementia, two risk factors with an $65 \%$ increased risk and three or more with a doubling of risk. Our results support the need for clinicians, public health organisations and individuals to keep risk factor exposure to a minimum and even where risk factors are present to prevent further accrual.

Acknowledgements The authors gratefully acknowledge the contribution and commitment of the participants and study teams from each of the constituent studies used in the review.

Contributors RP conceived and designed the study, carried out the data extraction, analysis and drafted the manuscript. $A B$ helped design the study and the search strategy and commented on the manuscript. KR helped design the study, and commented on the manuscript. JP helped design the study, extracted the data and commented on the manuscript. CDE advised on the statistical methods and commented on the manuscript. KJA helped design the study and commented on the manuscript. All authors had full access to study data.

Funding No funding was received specifically for this work. RP is funded by the Australian Dementia Collaborative Research Centre. AB's input into the literature search and review design was undertaken under his University of Sheffield employment contract. KR is funded through the Dalhousie Medical Research Foundation as the Kathryn Allen Weldon Professor of Alzheimer's Research and receives research funding from the Canadian Institutes of Health Research, the 
Canadian Frailty Network and the Fountain Family Research Fund of the Queen Elizabeth II Health Sciences Centre. JP received no support from any organisation for the submitted work. KJA is funded by NHMRC Fellowship APP1102694.

Competing interests $\mathrm{RP}, \mathrm{AB}, \mathrm{JP}, \mathrm{CDE}, \mathrm{KJA}$ report no disclosures. KR founded DGl Clinical, which has contracts with pharma for individualised outcome measurement and for data analytics, including in dementia studies with Otsuka and Roche. In 2017, he participated in an Advisory Board meeting on dementia for Lundbeck and in 2014 spoke at a satellite symposium at the Alzheimer Association International Conference, sponsored by Nutricia.

Patient consent Not required.

Provenance and peer review Not commissioned; externally peer reviewed.

Data sharing statement The data supporting the results are publicly available in the published literature. RP affirms that the manuscript is an accurate honest and transparent account of the study being reported. No important aspects of the study have been omitted, any discrepancies between the study as planned and registered are explained. Funding bodies had no role in the inception, design, completion or publication of this work.

Open access This is an open access article distributed in accordance with the Creative Commons Attribution Non Commercial (CC BY-NC 4.0) license, which permits others to distribute, remix, adapt, build upon this work non-commercially, and license their derivative works on different terms, provided the original work is properly cited, appropriate credit is given, any changes made indicated, and the use is non-commercial. See: http://creativecommons.org/licenses/by-nc/4.0/.

\section{REFERENCES}

1. Alzheimer's Disease International. World alzheimer report 2014: dementia and risk reduction. 2014 http://www.alz.co.uk/research/ world-report-2014.

2. Lincoln $\mathrm{P}$, Fenton $\mathrm{K}$, Alessi $\mathrm{C}$, et al. The Blackfriars Consensus on brain health and dementia. The Lancet 2014;383:1805-6.

3. Poortinga $W$. The prevalence and clustering of four major lifestyle risk factors in an English adult population. Prev Med 2007;44:124-8.

4. Griffin B, Sherman KA, Jones M, et al. The clustering of health behaviours in older australians and its association with physical and psychological status, and Sociodemographic Indicators. Annals of Behavioral Medicine 2014;48:205-14.

5. Morris LJ, D'Este C, Sargent-Cox K, et al. Concurrent lifestyle risk factors: Clusters and determinants in an Australian sample. Prev Med 2016;84:1-5.

6. Ngandu T, Lehtisalo J, Solomon A, et al. A 2 year multidomain intervention of diet, exercise, cognitive training, and vascular risk monitoring versus control to prevent cognitive decline in at-risk elderly people (FINGER): a randomised controlled trial. The Lancet 2015;385:2255-63.

7. Siervo M, Harrison SL, Jagger C, et al. Metabolic syndrome and longitudinal changes in cognitive function: a systematic review and meta-analysis. Journal of Alzheimer's Disease 2014;41:151-61.

8. Hao Z, Wu B, Wang D, et al. Association between metabolic syndrome and cognitive decline: a systematic review of prospective population-based studies. Acta Neuropsychiatr 2011;23:69-74.

9. Downer B, Veeranki SP, Wong R. A late life risk index for severe cognitive impairment in Mexico. Journal of Alzheimer's Disease 2016;52:191-203.

10. Aarts S, van den Akker M, Tan FES, et al. Influence of multimorbidity on cognition in a normal aging population: a 12-year follow-up in the Maastricht Aging Study. Int J Geriatr Psychiatry 2011;26:1046-53.

11. Kåreholt I, Lennartsson C, Gatz M, et al. Baseline leisure time activity and cognition more than two decades later. Int J Geriatr Psychiatry 2011;26:65-74.

12. Agrigoroaei S, Lachman ME. Cognitive functioning in midlife and old age: combined effects of psychosocial and behavioral factors. J Gerontol B Psychol Sci Soc Sci 2011;66 Suppl 1:i130-i140.

13. Iyer GK, Alladi S, Bak TH, et al. Dementia in developing countries: Does education play the same role in India as in the West? Dement Neuropsychol 2014;8:132-40.

14. Viticchi G, Falsetti L, Buratti L, et al. Framingham risk score can predict cognitive decline progression in Alzheimer's disease. Neurobiol Aging 2015;36:2940-5.

15. Ogunmoroti O, Allen NB, Cushman M, et al. Association between life's simple 7 and noncardiovascular disease : the multi-ethnic stu dy of Atherosclerosis. J Am Heart Assoc 2016;5:e003954.
16. Mielke MM, Rosenberg PB, Tschanz J, et al. Vascular factors predict rate of progression in Alzheimer disease. Neurology 2007;69:1850-8.

17. Wang R, Fratiglioni L, Laukka EJ, et al. Effects of vascular risk factors and APOE 4 on white matter integrity and cognitive decline. Neurology 2015;84:1128-35.

18. Shaw BA, Agahi N. Smoking and physical inactivity patterns during midlife as predictors of all-cause mortality and disability: a 39-year prospective study. Eur J Ageing 2014;11:195-204.

19. Song X, Mitnitski A, Rockwood K. Index variables for studying outcomes in vascular cognitive impairment. Neuroepidemiology 2005;25:196-204.

20. Tang Z, Zhou T, Luo Y, et al. Risk factors for cerebrovascular disease mortality among the elderly in beijing: a competing risk analysis. PLoS One 2014;9:e87884.

21. Soto-Gordoa M, Arrospide A, Moreno-Izco F, et al. Projecting burden of dementia in spain, 2010-2050: impact of modifying risk factors. Journal of Alzheimer's Disease 2015;48:721-30.

22. Kim S, Cherbuin N, Anstey KJ. Assessing reliability of short and tick box forms of the ANU-ADRI: Convenient alternatives of a selfreport Alzheimer's disease risk assessment. Alzheimers Dement 2016;2:93-8.

23. Adams ML, Grandpre J. Dose-response gradients between a composite measure of six risk factors and cognitive decline and cardiovascular disease. Prev Med 2016;91:329-34.

24. Rosal MC, Ockene JK, Ma Y, et al. Behavioral risk factors among members of a health maintenance organization. Prev Med 2001;33:586-94.

25. Russ TC, Hamer M, Stamatakis E, et al. Does the Framingham cardiovascular disease risk score also have predictive utility for dementia death? An individual participant meta-analysis of 11,887 men and women. Atherosclerosis 2013;228:256-8.

26. Katon W, Pedersen HS, Ribe AR, et al. Effect of depression and diabetes mellitus on the risk for dementia. JAMA Psychiatry 2015;72:612-9.

27. Watts AS, Loskutova N, Burns JM, et al. Metabolic syndrome and cognitive decline in early alzheimer's disease and healthy older ad ults. Journal of Alzheimer's Disease 2013;35:253-65.

28. S. Laitala V, Kaprio J, Koskenvuo M, et al. Association and causal relationship of midlife obesity and related metabolic disorders with old age cognition. Current Alzheimer Research 2011;8:699-706.

29. Akbaraly TN, Kivimaki M, Shipley MJ, et al. Metabolic syndrome over 10 years and cognitive functioning in late midlife: the Whitehall Il study. Diabetes Care 2010;33:84-9.

30. Singh-Manoux A, Hillsdon M, Brunner E, et al. Effects of physical activity on cognitive functioning in middle age: evidence from the whitehall ii prospective cohort study. Am J Public Health 2005;95:2252-8.

31. Fung AW, Leung GT, Lam LC. Modulating factors that preserve cognitive function in healthy ageing. East Asian Arch Psychiatry 2011;21:152-6.

32. Prus SG. Age, SES, and health: a population level analysis of health inequalities over the lifecourse. Sociol Health IIIn 2007;29:275-96.

33. Strand BH, Rosness TA, Engedal K, et al. Interaction of apolipoprotein e genotypes, lifestyle factors and future risk of dementia-related mortality: the cohort of Norway (CONOR). Dement Geriatr Cogn Disord 2015;40:137-47.

34. Gureje O, Oladeji BD, Abiona T, et al. Profile and determinants of successful aging in the lbadan Study of Ageing. J Am Geriatr Soc 2014;62:836-42.

35. Luck T, Luppa M, Briel S, et al. Mild cognitive impairment: incidence and risk factors: results of the leipzig longitudinal study of the aged. J Am Geriatr Soc 2010;58:1903-10.

36. Newson RS, Kemps EB. General lifestyle activities as a predictor of current cognition and cognitive change in older adults: a crosssectional and longitudinal examination. J Gerontol B Psychol Sci Soc Sci 2005;60:P113-P120.

37. Luo Y, Waite LJ. The impact of childhood and adult ses on physical, mental, and cognitive well-being in later life. The Journals of Gerontology: Series B 2005;60:S93-S101.

38. Comijs HC, Kriegsman DM, Dik MG, et al. Somatic chronic diseases and 6-year change in cognitive functioning among older persons. Arch Gerontol Geriatr 2009;48:191-6.

39. Wilson RS, Scherr PA, Bienias JL, et al. Socioeconomic characteristics of the community in childhood and cognition in old age. Exp Aging Res 2005;31:393-407.

40. Morrow LA, Snitz BE, Rodriquez EG, et al. High medical comorbidity and family history of dementia is associated with lower cognitive function in older patients. Fam Pract 2009;26:339-43. 
41. Vemuri P, Lesnick TG, Przybelski SA, et al. Vascular and amyloid pathologies are independent predictors of cognitive decline in normal elderly. Brain 2015;138:761-71.

42. Duff K, Mold J, Roberts M, et al. Medical burden and cognition in older patients in primary care: Selective deficits in attention. Archives of Clinical Neuropsychology 2007;22:569-75.

43. Burke SL, Maramaldi P, Cadet T, et al. Neuropsychiatric symptoms and Apolipoprotein E: Associations with eventual Alzheimer's disease development. Arch Gerontol Geriatr 2016;65:231-8.

44. Fors S, Agahi N, Shaw BA. Paying the price? The impact of smoking and obesity on health inequalities in later life. Scand $J$ Public Health 2013;41:134-41.

45. Karp A, Paillard-Borg S, Wang H-X, et al. Mental, physical and social components in leisure activities equally contribute to decrease dementia risk. Dement Geriatr Cogn Disord 2006;21:65-73.

46. Harrison SL, de Craen AJM, Kerse N, et al. Predicting risk of cognitive decline in very old adults using three models: the framingham stroke risk profile; the cardiovascular risk factors, aging, and dementia model; and oxi-inflammatory biomarkers. J Am Geriatr Soc 2017;65:381-9.

47. Andrews SJ, Eramudugolla R, Velez Jl, et al. Validating the role of the Australian National University Alzheimer's Disease Risk Index (ANU-ADRI) and a genetic risk score in progression to cognitive impairment in a population-based cohort of older adults followed for 12 years. Alzheimers Res Ther 2017;9:16.

48. Viswanathan A, Macklin EA, Betensky R, et al. The influence of vascular risk factors and stroke on cognition in late life: analysis of the nacc cohort. Alzheimer Dis Assoc Disord 2015;29:287-93.

49. Jefferson AL, Hohman TJ, Liu D, et al. Adverse vascular risk is related to cognitive decline in older adults. Journal of Alzheimer's Disease 2015;44:1361-73.

50. Levin BE, Llabre MM, Dong C, et al. Modeling metabolic syndrome and its association with cognition: the northern manhattan study. Journal of the International Neuropsychological Society 2014;20:951-60.

51. Lorius N, Locascio JJ, Rentz DM, et al. Vascular disease and risk factors are associated with cognitive decline in the alzheimer disease spectrum. Alzheimer Dis Assoc Disord 2015;29:18-25.

52. Durazzo TC, Mattsson N, Weiner MW. Interaction of cigarette smoking history with apoe genotype and age on amyloid level, glucose metabolism, and neurocognition in cognitively normal elders. Nicotine Tob Res 2016;18:204-11.

53. Yaffe K, Vittinghoff E, Pletcher MJ, et al. Early adult to midlife cardiovascular risk factors and cognitive function. Circulation 2014;129:1560-7.

54. Moroney JT, et al. Low-density lipoprotein cholesterol and the risk of dementia with stroke. JAMA 1999;282:254-60.

55. Barnes DE, Covinsky KE, Whitmer RA, et al. Predicting risk of dementia in older adults: The late-life dementia risk index. Neurology 2009;73:173-9.

56. Gallucci M, Mazzuco S, Ongaro F, et al. Body mass index, lifestyles, physical performance and cognitive decline: The "Treviso Longeva (Trelong)" study. J Nutr Health Aging 2013;17:378-84.

57. Downer B, Kumar A, Veeranki SP, et al. Mexican-american dementia nomogram: development of a dementia risk index for mexicanamerican older adults. J Am Geriatr Soc 2016;64:e265-e269.

58. Pankratz VS, Roberts RO, Mielke MM, et al. Predicting the risk of mild cognitive impairment in the Mayo Clinic Study of Aging. Neurology 2015;84:1433-42.

59. Monastero R, Palmer K, Qui C, et al. Heterogeneity in risk factors for cognitive impairment, no dementia: population-based longitudinal study from the kungsholmen project. The American Journal of Geriatric Psychiatry 2007;15:60-9.

60. Debette S, Seshadri S, Beiser A, et al. Midlife vascular risk factor exposure accelerates structural brain aging and cognitive decline. Neurology 2011;77:461-8.

61. Mielke MM, Leoutsakos J-M, Tschanz JT, et al. Interaction between vascular factors and the apoe $\varepsilon 4$ allele in predicting rate of progres sion in Alzheimer's Disease. Journal of Alzheimer's Disease 2011;26:127-34.

62. Kaffashian S, Dugravot A, Elbaz A, et al. Predicting cognitive decline: a dementia risk score vs. the Framingham vascular risk scores. Neurology 2013;80:1300-6.

63. Kivipelto M, Ngandu T, Laatikainen T, Winblad B, et al. Risk score for the prediction of dementia risk in 20 years among middle aged people: a longitudinal, population-based study. Lancet Neurol 2006;5:735-41.

64. Dregan A, Stewart R, Gulliford MC. Cardiovascular risk factors and cognitive decline in adults aged 50 and over: a population-based cohort study. Age Ageing 2013;42:338-45.
65. Virta JJ, Heikkilä K, Perola M, et al. Midlife cardiovascular risk factors and late cognitive impairment. Eur J Epidemiol 2013;28:405-16.

66. Warsch JRL, Rundek T, Paik MC, et al. Association between northern manhattan study global vascular risk score and successfu aging. J Am Geriatr Soc 2013;61:519-24.

67. Mitnitski A, Skoog I, Song X, et al. A vascular risk factor index in relation to mortality and incident dementia. Eur $J$ Neurol 2006;13:514-21.

68. Mehta HB, Mehta V, Tsai C-L, et al. Development and validation of the rxdx-dementia risk index to predict dementia in patients with type 2 diabetes and Hypertension. Journal of Alzheimer's Disease 2016;49:423-32.

69. Unverzagt FW, McClure LA, Wadley VG, et al. Vascular risk factors and cognitive impairment in a stroke-free cohort. Neurology 2011;77:1729-36

70. Hazzouri AZA, Haan MN, Neuhaus JM, et al. Cardiovascular risk score, cognitive decline, and dementia in older mexican americans: the role of sex and education. J Am Heart Assoc 2013;2:e004978.

71. Chou R-H, Chiu C-C, Huang C-C, et al. Prediction of vascular dementia and Alzheimer's disease in patients with atrial fibrillation or atrial flutter using CHADS2 score. Journal of the Chinese Medical Association 2016;79:470-6.

72. Kesse-Guyot E, Lassale C, Assmann KE, et al. Are different vascular risk scores calculated at midlife uniformly associated with subsequent poor cognitive performance? Atherosclerosis 2015;243:286-92.

73. Exalto LG, Quesenberry CP, Barnes D, et al. Midlife risk score for the prediction of dementia four decades later. Alzheimer's \& Dementia 2014;10:562-70.

74. Szoeke C, Lehert P, Henderson VW, et al. Predictive factors for verbal memory performance over decades of aging: data from the women's healthy ageing project. The American Journal of Geriatric Psychiatry 2016;24:857-67.

75. Takahashi PY, Caldwell CR, Targonski PV. Effect of vascular burden as measured by vascular indexes upon vascular dementia: a matched case-control study. Clin Interv Aging 2012;7:27-33.

76. McLennan SN, Mathias JL, Brennan LC, et al. Cognitive impairment predicts functional capacity in dementia-free patients with cardiovascular disease. J Cardiovasc Nurs 2010;25:390-7.

77. Lee Y, Back JH, Kim J, et al. Multiple socioeconomic risks and cognitive impairment in older adults. Dement Geriatr Cogn Disord 2010;29:523-9.

78. Lee Y, Back JH, Kim J, et al. Clustering of multiple healthy lifestyles among older Korean adults living in the community. Geriatr Gerontol Int 2012;12:515-23.

79. Nguyen H, Evans M, Zonderman A. Influence of medical conditions on executive and memory functions in low socioeconomic status African Americans. Archives of Clinical Neuropsychology 2007;22:689-98.

80. Falkowski J, Atchison T, DeButte-Smith M, et al. Executive functioning and the metabolic syndrome: a project frontier study. Archives of Clinical Neuropsychology 2014;29:47-53.

81. Scuteri A, Spazzafumo L, Cipriani L, et al. Depression, hypertension, and comorbidity: disentangling their specific effect on disability and cognitive impairment in older subjects. Arch Gerontol Geriatr 2011;52:253-7.

82. Bendini C, Angelini A, Salsi F, et al. Relation of neurocardiovascular instability to cognitive, emotional and functional domains. Arch Gerontol Geriatr 2007;44:69-74.

83. Turrell G, Lynch JW, Kaplan GA, et al. Socioeconomic position across the lifecourse and cognitive function in late middle age. $J$ Gerontol B Psychol Sci Soc Sci 2002;57:S43-S51.

84. Dowling NM, Gleason CE, Manson JE, et al. Characterization of vascular disease risk in postmenopausal women and its association with cognitive performance. PLoS One 2013;8:e68741.

85. Dik MG, Jonker C, Comijs HC, et al. Contribution of metabolic syndrome components to cognition in older individuals. Diabetes Care 2007;30:2655-60.

86. Love S, Miners S. Cerebrovascular disease in ageing and alzheimer's disease acta neuropathologica. 2016;131:645-58.

87. Stephan BCM, Brayne C. Assessing the risk of dementia in the aging population. Nat Rev Neurol 2009;5:417-8.

88. Kalmijn S, Foley D, White L, et al. Metabolic cardiovascular syndrome and risk of dementia in japanese-american elderly men. Arterioscler Thromb Vasc Biol 2000;20:2255-60.

89. Luchsinger JA, Reitz C, Honig LS, et al. Aggregation of vascular risk factors and risk of incident Alzheimer disease. Neurology 2005;65:545-51. 
90. Reis JP, Loria CM, Launer LJ, et al. Cardiovascular health through young adulthood and cognitive functioning in midlife. Ann Neurol 2013;73:170-9.

91. Gardener H, Wright CB, Dong C, et al. Ideal cardiovascular health and cognitive aging in the northern manhattan study. J Am Heart Assoc 2016;5:e002731.

92. Hildreth KL, Grigsby J, Bryant LL, et al. Cognitive decline and cardiometabolic risk among Hispanic and non-Hispanic white adults in the San Luis Valley Health and Aging Study. J Behav Med 2014;37:332-42.

93. Whitmer RA, Sidney S, Selby J, et al. Midlife cardiovascular risk factors and risk of dementia in late life. Neurology 2005;64:277-81.

94. Schneider BC, Gross AL, Bangen KJ, et al. Association of vascular risk factors with cognition in a multiethnic sample. J Gerontol $B$ Psychol Sci Soc Sci 2015;70:532-44.

95. Norton MC, Dew J, Smith H, et al. Lifestyle behavior pattern is associated with different levels of risk for incident dementia and alzheimer's disease : the cache county study. J Am Geriatr Soc 2012;60:405-12.

96. Elias MF, Elias PK, Sullivan LM, et al. Lower cognitive function in the presence of obesity and hypertension: the Framingham heart study. Int J Obes 2003;27:260-8.

97. Scarmeas $\mathrm{N}$, et al. Physical activity, diet, and risk of alzheimer disease. JAMA 2009;302:627-37.

98. Rönnemaa $E$, Zethelius B, Lannfelt L, et al. Vascular risk factors and dementia: 40-year follow-up of a population-based cohort. Dement Geriatr Cogn Disord 2011;31:460-6.

99. Persson N, Viitanen M, Almkvist O, et al. A principal component model of medical health: Implications for cognitive deficits and decline among adults in a population-based sample. $J$ Health Psychol 2013;18:1268-87.

100. Qiu C, Xu W, Winblad B, et al. Vascular risk profiles for dementia and alzheimer's disease in very old people: a population-based longitudinal study. Journal of Alzheimer's Disease 2010;20:293-300.

101. Kivipelto M, Ngandu T, Fratiglioni L, et al. Obesity and vascular risk factors at midlife and the risk of dementia and alzheimer disease. Arch Neurol 2005;62:1556-60.

102. Reijmer YD, van den Berg E, van Sonsbeek S, et al. Dementia risk score predicts cognitive impairment after a period of 15 years in a nondemented population. Dement Geriatr Cogn Disord 2011;31:152-7.

103. Schiepers OJG, Köhler S, Deckers K, et al. Lifestyle for Brain Health (LIBRA): a new model for dementia prevention. Int $J$ Geriatr Psychiatry 2018;33.

104. Hessler JB, Ander KH, Brönner M, et al. Predicting dementia in primary care patients with a cardiovascular health metric: a prospective population-based study. BMC Neurol 2016;16:116.

105. Kesse-Guyot E, Andreeva VA, Lassale C, et al. Clustering of midlife lifestyle behaviors and subsequent cognitive function: a longitudinal study. Am J Public Health 2014;104:e170-e177.

106. Hagger-Johnson G, Sabia S, Brunner EJ, et al. Combined impact of smoking and heavy alcohol use on cognitive decline in early old age: Whitehall II prospective cohort study. Br J Psychiatry 2013;203:120-5.

107. Sabia S, Nabi H, Kivimaki M, et al. Health behaviors from early to late midlife as predictors of cognitive function: The Whitehall II study. Am J Epidemiol 2009;170:428-37.

108. Anstey KJ, Sargent-Cox K, Garde E, et al. Cognitive development over 8 years in midlife and its association with cardiovascular risk factors. Neuropsychology 2014;28:653-65.

109. Lee Y, Kim J, Back JH. The influence of multiple lifestyle behaviors on cognitive function in older persons living in the community. Prev Med 2009;48:86-90.

110. Greenland S, Longnecker MP. Methods for trend estimation from summarized dose-response data. with applications to metaanalysis, American Journal of Epidemioly 1992;135:1301-9.
111. Stocks T, Bjørge T, Ulmer $\mathrm{H}$, et al. Metabolic risk score and cancer risk: pooled analysis of seven cohorts. Int J Epidemiol 2015;44:1353-63.

112. Ding $\mathrm{D}$, Rogers $\mathrm{K}$, van der Ploeg $\mathrm{H}$, et al. Traditional and emerging lifestyle risk behaviors and all-cause mortality in middle-aged and older adults: evidence from a large population-based Australian Cohort. PLoS Med 2015;12:e1001917.

113. Payne RA. Cardiovascular risk. Br J Clin Pharmacol 2012;74:396-410.

114. Damen JA, Hooft L, Schuit E, et al. Prediction models for cardiovascular disease risk in the general population: systematic review. BMJ 2016;353:i2416.

115. Gottesman RF, Schneider AL, Zhou Y, et al. Association between midlife vascular risk factors and estimated brain amyloid deposition. JAMA 2017;317:1443-50.

116. Peters R, Peters J, Booth A, et al. Is air pollution associated with increased risk of cognitive decline? A systematic review. Age Ageing 2015;44:755-60.

117. Clifford A, Lang L, Chen R, et al. Exposure to air pollution and cognitive functioning across the life course-A systematic literature review. Environ Res 2016;147:383-98.

118. Rovio SP, Pahkala K, Nevalainen J, et al. Cardiovascular risk factors from childhood and midlife cognitive performance. J Am Coll Cardiol 2017;69:2279-89.

119. Yang Z, Slavin MJ, Sachdev PS. Dementia in the oldest old. Nat Rev Neurol 2013;9:382-93.

120. Fontana L, Kennedy BK, Longo VD, et al. Medical research: treat ageing. Nature 2014;511:405-7.

121. Howlett SE, Rockwood K. Ageing: Develop models of frailty. Nature 2014;512:253.

122. Wallace LM, Theou O, Kirkland SA, et al. Accumulation of nontraditional risk factors for coronary heart disease is associated with incident coronary heart disease hospitalization and death. PLOS One 2014;9:e90475.

123. Zhang WB, Pincus Z. Predicting all-cause mortality from basic physiology in the Framingham Heart Study. Aging Cell 2016;15:39-48.

124. Song X, Mitnitski A, Rockwood K. Age-related deficit accumulation and the risk of late-life dementia. Alzheimers Res Ther 2014;6(58):54.

125. Armstrong JJ, Mitnitski A, Andrew MK, et al. Cumulative impact of health deficits, social vulnerabilities, and protective factors on cognitive dynamics in late life: a multistate modeling approach. Alzheimers Res Ther 2015;7:38.

126. Godin J, Armstrong JJ, Rockwood K, et al. Dynamics of frailty and cognition after age 50: why it matters that cognitive decline is mostly seen in old age. J Alzheimers Dis 2017;58:231-42.

127. López-Otín C, Blasco MA, Partridge L, et al. The hallmarks of aging Cell 2013;153:1194-217.

128. Howlett SE, Rockwood K. New horizons in frailty: ageing and the deficit-scaling problem. Age Ageing 2013;42:416-23.

129. Mitnitski A, Collerton J, Martin-Ruiz C, et al. Age-related frailty and its association with biological markers of ageing. BMC Med 2015;13:161.

130. Howlett SE, Rockwood MR, Mitnitski A, et al. Standard laboratory tests to identify older adults at increased risk of death. BMC Med 2014;12:171.

131. Wallace LM, Ferrara M, Brothers TD, et al. Lower frailty is associated with successful cognitive aging among older adults with HIV. AIDS Res Hum Retroviruses 2017;33:157-63.

132. Schoufour JD, Mitnitski A, Rockwood K, et al. Predicting disabilities in daily functioning in older people with intellectual disabilities using a frailty index. Res Dev Disabil 2014;35:2267-77.

133. Davis DH, Muniz-Terrera G, Keage HA, et al. Association of delirium with cognitive decline in late life: a neuropathologic study of 3 population-based cohort studies. JAMA Psychiatry 2017;74:244-51. 